This is an electronic reprint of the original article. This reprint may differ from the original in pagination and typographic detail.

Author(s): Kouva, Sonja; Honkala, Karoliina; Lefferts, Leon; Kanervo, Jaana

Title: $\quad$ Review: monoclinic zirconia, its surface sites and their interaction with carbon monoxide

Year: $\quad 2015$

Version:

Please cite the original version:

Kouva, S., Honkala, K., Lefferts, L., \& Kanervo, J. (2015). Review: monoclinic zirconia, its surface sites and their interaction with carbon monoxide. Catalysis Science \& Technology, 5(7), 3473-3490. https://doi.org/10.1039/C5CY00330J

All material supplied via JYX is protected by copyright and other intellectual property rights, and duplication or sale of all or part of any of the repository collections is not permitted, except that material may be duplicated by you for your research use or educational purposes in electronic or print form. You must obtain permission for any other use. Electronic or print copies may not be offered, whether for sale or otherwise to anyone who is not an authorised user. 


\section{Catalysis Science \& Technology}

\section{Accepted Manuscript}

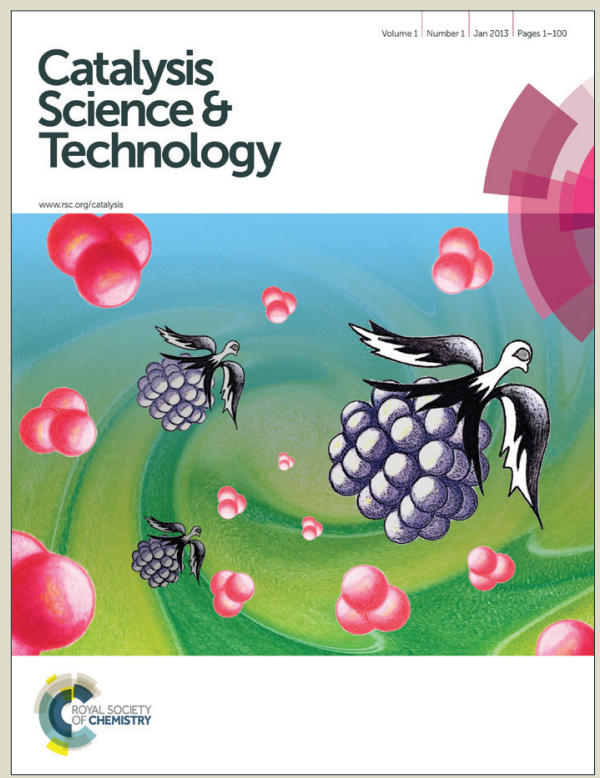

This is an Accepted Manuscript, which has been through the Royal Society of Chemistry peer review process and has been accepted for publication.

Accepted Manuscripts are published online shortly after acceptance, before technical editing, formatting and proof reading. Using this free service, authors can make their results available to the community, in citable form, before we publish the edited article. We will replace this Accepted Manuscript with the edited and formatted Advance Article as soon as it is available.

You can find more information about Accepted Manuscripts in the Information for Authors.

Please note that technical editing may introduce minor changes to the text and/or graphics, which may alter content. The journal's standard Terms \& Conditions and the Ethical guidelines still apply. In no event shall the Royal Society of Chemistry be held responsible for any errors or omissions in this Accepted Manuscript or any consequences arising from the use of any information it contains. 


\title{
Review: Monoclinic zirconia, its surface sites and their interaction with carbon monoxide
}

\author{
Sonja Kouva, ${ }^{*}, a$ Karoliina Honkala, ${ }^{b}$ Leon Lefferts, ${ }^{a, c}$ and Jaana Kanervo ${ }^{a}$
}

\author{
Received Xth $X X X X X X X X X X 2015$, Accepted Xth $X X X X X X X X X 201 X$ \\ First published on the web Xth $X X X X X X X X X X 201 X$ \\ DOI: $10.1039 / b 000000 x$
}

This review concerns monoclinic zirconia, its surface sites and their probing with carbon monoxide. The surface sites and their modifications using thermal treatments with vacuum or reactive gases are also included. In this work, we present information on the nature and manipulation of hydroxyl species and their quantities on the surface, the different types of cationic sites where $\mathrm{CO}$ is adsorbed linearly and their energetics, as well as the surface sites and dynamics of formate formation. We also compare the surface concentrations of the different surface species to better understand the extent and nature of the interactions. Finally, we discuss some of the remaining open questions and how to approach them.

\section{Introduction}

Zirconium oxide has gained interest both as a catalyst support and a catalyst on its own, mostly due to its weak acid and basic sites ${ }^{1}$ and stability under oxidizing and reducing atmospheres ${ }^{2}$. It has been an interesting catalyst material especially for biomass-related reactions that are actively investigated, as the future is bright for non-fossil fuels and chemicals. Biomass-related reaction networks usually include carbon oxides, as both carbon and oxygen are largely abundant in the starting material.

Monoclinic zirconia (also known as baddeleyite) is an oxide typically covered with hydroxyl species, similar to many metal oxides ${ }^{3}$ used as catalysts and catalyst support materials. The structure of monoclinic zirconia provides a more versatile surface than the other polymorphs (cubic, tetragonal) due to a less symmetrical lattice ${ }^{4}$. The surface sites on monoclinic zirconia include hydroxyls ${ }^{5}$, oxygen vacancies ${ }^{6}$, coordinatively unsaturated (c.u.s.) $\mathrm{Zr}-\mathrm{O}$ pairs ${ }^{7}$, and Lewis acid sites $\left(\mathrm{Zr}^{3+}\right.$, $\left.\mathrm{Zr}^{4+}\right)^{8}$. The hydroxyl groups on the surface can be manipulated by thermal treatment in vacuum or in different atmospheres ${ }^{9}$, which are often necessary for catalytic applications, e.g., in methanol synthesis ${ }^{10}$. Additionally, monoclinic zirconia has been suggested as a support for water-gas shift reaction catalysts with gold, platinum and copper ${ }^{11-13}$, and for reforming with platinum, nickel, cobalt and copper ${ }^{14,15}$.

Since 2006, monoclinic zirconia has been prepared also in nanoshapes, including nanorods ${ }^{16,17}$ and nanosheets ${ }^{16}$. Using the nanoshapes in catalysis might be beneficial due to their well-defined surface sites; thus their selectivity might be more easily linked to the exposed surfaces than those of traditional catalysts in polycrystalline form.

Carbon monoxide interacts with monoclinic zirconia both on the clean surface with few or no hydroxyls ${ }^{18}$, as well as on the hydroxylated surface ${ }^{19,20}$. The surface hydroxyl groups seem to play an important role in the interaction of $\mathrm{CO}$ with zirconia: as a site for forming formates ${ }^{5,7,20-23}$ and bicarbonates ${ }^{22,24-26}$ but also inhibiting the formation of adsorbed linear $\mathrm{CO}$ species ${ }^{27}$. The main adsorbed $\mathrm{CO}$ species are linearly adsorbed $\mathrm{CO}$ at room temperature and below and formate species above $100^{\circ} \mathrm{C}$, the first one desorbing reversibly ${ }^{27}$ and the second one decomposing both reversibly back to gas-phase $\mathrm{CO}$ and irreversibly to $\mathrm{CO}_{2}$ and $\mathrm{H}_{2}{ }^{20,21,28}$.

The interaction of carbon monoxide with zirconium oxide has been studied actively since the $1970 \mathrm{~s}^{5,18,21,23,29,30}$. Due to differences in zirconia materials and their pretreatments, experimental setups and conditions, interpreting and comparing the obtained results is not straightforward. Most of the studies on the interaction with $\mathrm{CO}$ have been carried out using infrared spectroscopy $5,18,19,22-24$. However, studies using other techniques, such as temperature-programmed methods ${ }^{20,21,28,30}$, calorimetry $27,31,32$, and gravimetry ${ }^{33,34}$, as well as theoretical studies ${ }^{22,28}$ have been published.

The focus of this work is in the monoclinic polymorph of zirconia instead of the whole spectrum of zirconia materials: doped (including sulphated), tetragonal and cubic zirconia, to name the most significant zirconias excluded from this review. This choice is made for simplicity and clarity, as monoclinic and tetragonal zirconias differ in, e.g., surface hydroxyl species ${ }^{7,25}$ and acidity/basicity ${ }^{7,24,30}$, further demonstrated in their interactions with $\mathrm{CO}^{7,25,30}$ and in their catalytic activity, e.g., in water-gas shift ${ }^{11,12}$. More information can also be found in the reviews by Dyrek et al. ${ }^{35}$ and Hadjiivanov ${ }^{36}$.Most of the pre-1993 works included in this paper were reviewed 20 years ago by Nawrocki et al. ${ }^{37}$ in the context of chromatography; this review is providing an update 
with work reported since 1993, from the perspective of catalysis.

\section{Preparation, structure, and surfaces}

\subsection{Preparation}

Zirconium oxide can be prepared, e.g., via hydrolysis from zirconium isopropylate $\left(\mathrm{Zr}\left(\mathrm{OCH}\left(\mathrm{CH}_{3}\right)_{2}\right)_{4}\right)^{8,18,27,38-40}$ or zirconium oxychloride $\left(\mathrm{ZrOCl}_{2}\right)^{25,30,41-43}$, and also from zirconium oxynitrate $\left(\mathrm{ZrO}\left(\mathrm{NO}_{3}\right)_{2}\right)^{42-44}$ and zirconium tetrachloride $\left(\mathrm{ZrCl}_{4}\right)^{10,45}$. Yamaguchi introduces the processes starting from natural ores (zircon $\left(\mathrm{ZrSiO}_{4}\right)$, baddeleyite) to zirconium oxide preparation ${ }^{2}$. Origin of the zirconia samples referred to in this review, with their preparation conditions and surface areas are presented in Table 1 to aid the reader by presenting the key properties of the materials used. Note that the applied pretreatment conditions might differ from the preparation conditions.

\subsection{Crystal structure and surfaces}

The unit cell of monoclinic zirconia is face-centered (spacegroup $C_{2 h}^{5}$ ), consisting of $4 \mathrm{Zr}$ atoms and $8 \mathrm{O}$ atoms ${ }^{72}$. In the bulk all $\mathrm{Zr}$ atoms are seven-fold coordinated to three threefold coordinated oxygen atoms and four four-fold coordinated oxygen atoms ${ }^{73}$. Based on theory, the coordination numbers on the surface differ, e.g., on the (111) surface some of the zirconium atoms are only six-fold coordinated and some of the oxygen atoms are three- or two-fold coordinated instead of four- or three-fold coordination ${ }^{74}$. On the (111) surface, some zirconium atoms can be even five-fold coordinated ${ }^{74}$. The experimentally determined lattice parameters are $a=5.17 \AA$, $b=5.23 \AA$, and $c=5.34 \AA$, and the angle $\gamma=99.3^{\circ} 75$.

Monoclinic zirconia has altogether nine inequivalent crystalline directions: [001], [010], [100], [110], [101], [011], [101], [111] and [1111] ${ }^{4}$. Warble reported (110), (100) and (111) surfaces to be exhibited in transmission electron microscopy $(\text { TEM })^{76}$. The $(111)^{39,40},(001)^{39,40}$ and $(011)^{40}$ planes have been reported based on high-resolution TEM (HRTEM) images. Theoretically, the most stable surface for monoclinic zirconia is the (111) surface ${ }^{4}$. The difference between the theoretically most stable surfaces and the experimentally observed surfaces might be due to inaccuracy in either method, and it is not clear whether the particle size or, e.g., the degree of surface hydration play a role. In nanocrystals, the (011) surface seems most abundant in TEM, while also (111), (111) and (001) surfaces have been observed ${ }^{77}$. The ideal (111), (111), (001) and (011) surfaces are shown in Figure 1. The atom positions are those of the bulk structure assuming no reconstruction takes place.
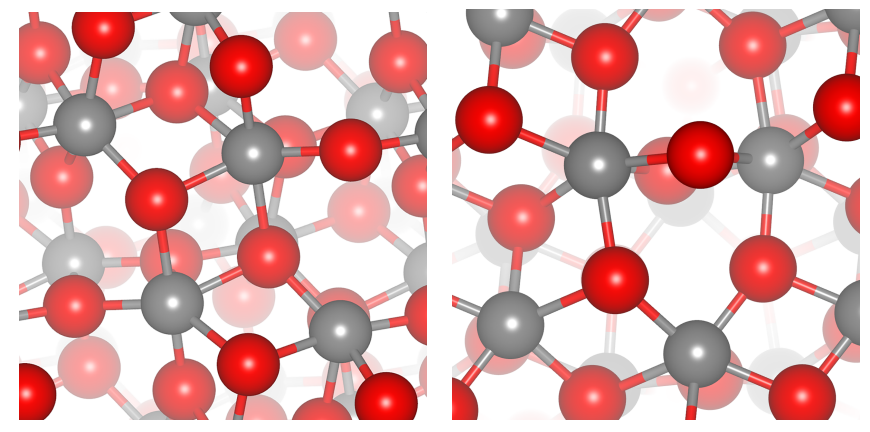

(a) The (111) surface.

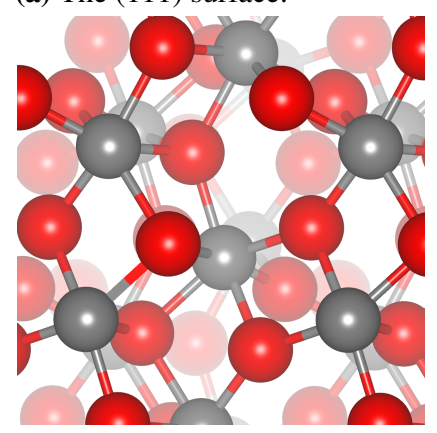

(b) The (111) surface.

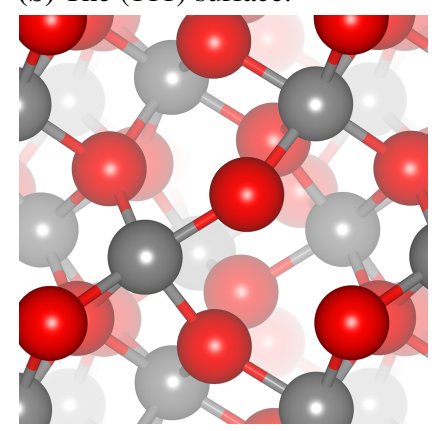

(c) The (011) surface.

(d) The (001) surface.

Fig. 1 Ideal surfaces of monoclinic $\mathrm{ZrO}_{2}$, top view, $\mathrm{Zr}$ atoms are grey and $\mathrm{O}$ atoms red. The atoms further in the lattice are shaded lighter than those on the surface. The surfaces were visualized using VESTA software ${ }^{78}$.

Jung et al. report that the crystallographic structure of zirconia, instead of crystallite size or calcination temperature, is the most significant factor for determining the nature and density of the surface sites suitable for $\mathrm{CO}_{2}$ and $\mathrm{NH}_{3}$ adsorption, i.e., the basic and acidic surface sites ${ }^{4}$. Monoclinic zirconia has a higher $\mathrm{CO}$ adsorption capacity than tetragonal $\mathrm{ZrO}_{2}$, which is attributed to its higher Lewis acidity and basicity ${ }^{30}$. The tetragonal structure is more symmetrical than the monoclinic one ${ }^{4}$, leading to a smaller number of different surfaces and thus possibly also to less versatile surface site types.

Thermal treatment tends to increase the crystal size of monoclinic zirconia. Increasing the calcination temperature by $300-500^{\circ} \mathrm{C}$ can lead to a particle size of three or even four times the original ${ }^{40,64}$. Auger electron spectroscopy (AES) ${ }^{79}$ shows that the surface $\mathrm{O} / \mathrm{Zr}$ ratio decreases from the stoichiometric 2 down to 1.1 with evacuation at $427^{\circ} \mathrm{C}$ and $727^{\circ} \mathrm{C}$, respectively. The surface reduction is very fast, and extending the time to one hour in ultra-high vacuum (UHV) does not affect the surface ${ }^{79}$. With $\mathrm{H}_{2}$ the surface seems unreducible even at 900 Torr and $900^{\circ} \mathrm{C}$ while atomic hydrogen reduces the surface already at $750^{\circ} \mathrm{C}$ and $\mathrm{H}_{2}$ pressure of $5 \mu$ Torr prior to atomization ${ }^{80}$. The ineffectiveness of $\mathrm{H}_{2}$ compared to UHV in surface reduction is rather unexpected, yet atomic hydrogen 
Table 1 Origin, preparation conditions and surface area of the zirconia samples a

\begin{tabular}{|c|c|c|c|c|}
\hline Material & $T_{\text {calc }}\left({ }^{\circ} \mathrm{C}\right)$ & Atmosphere & $\mathrm{A}_{s}\left(\mathrm{~m}^{2} / \mathrm{g}\right)$ & Ref. \\
\hline$\overline{\text { Decomposition of } \mathrm{ZrO}\left(\mathrm{NO}_{3}\right)_{2} \cdot x \mathrm{H}_{2} \mathrm{O}}$ & $300 \& 300$ & air \& $10 \% \mathrm{H}_{2}$ & 20 & 42,43 \\
\hline Hydrolysis of $\mathrm{ZrOCl}_{2}$ & 600 & air, $4 \mathrm{~h}$ & - & 9 \\
\hline Hydrolysis of $\mathrm{ZrOCl}_{2}$ & $300 \& 700$ & $\mathrm{O}_{2}, 5 \mathrm{~h}$ & $110 \& 19$ & 25,30 \\
\hline Hydrolysis of $\mathrm{ZrOCl}_{2}$ & $700 \& 300-550$ & calc. \& vacuum, air (1h), $\mathrm{H}_{2}$, vacuum & 44 & 29 \\
\hline Hydrolysis of $\mathrm{ZrOCl}_{2}$ & $800 \& 1000$ & vacuum, $10 \mathrm{~min} \&$ air, $6 \mathrm{~h}$ & - & 46 \\
\hline Hydrolysis of $\mathrm{ZrO}\left(\mathrm{NO}_{3}\right)_{2}$ & $500 \& 800$ & air, $5 \mathrm{~h} \&$ vacuum, $5 \mathrm{~h}$ & - & 47 \\
\hline Hydrolysis of $\mathrm{ZrO}\left(\mathrm{NO}_{3}\right)_{2}$ & $700 \& 500 \& 700$ & calc., $3 \mathrm{~h} \& \mathrm{O}_{2}, 10 \mathrm{~h} \&$ vac., $20 \mathrm{~min}$ & $58^{\mathrm{c}}$ & 48 \\
\hline Hydrolysis of $\mathrm{ZrO}\left(\mathrm{NO}_{3}\right)_{2}$ & $500 \& 500 \& 730$ & calc., $3 \mathrm{~h} \& \mathrm{O}_{2}$, overnight $\&$ vac., $20 \mathrm{~min}$ & - & 49 \\
\hline Hydrolysis of $\mathrm{ZrO}\left(\mathrm{NO}_{3}\right)_{2}$ & $530 / 710$ & air, $3 \mathrm{~h}$ & $70 / 58$ & 26 \\
\hline Hydrolysis of $\mathrm{Zr}$ isopropylate & 447 & calcination & $81^{\mathrm{c}}$ & 50 \\
\hline \multirow[t]{2}{*}{ Hydrolysis of $\mathrm{Zr}$ isopropylate } & $447 \& 597$ & calcination $\&$ vacuum, $2 \mathrm{~h}$ & 82 & 18 \\
\hline & $447 \& 27-397$ & calcination $\&$ vacuum, $2 \mathrm{~h}$ & $92\left(397^{\circ} \mathrm{C}\right)$ & 18 \\
\hline \multirow[t]{2}{*}{ Hydrolysis of $\mathrm{Zr}$ isopropylate } & $447 \& 797$ & calc. \& vac., $2 \mathrm{~h}+50$ torr $\mathrm{O}_{2}, 30 \mathrm{~min}$ & 36 & 27 \\
\hline & $447 \& 397-597$ & calc. $\&$ vac., $2 \mathrm{~h}+50$ torr $\mathrm{O}_{2}, 30 \mathrm{~min}$ & $80-90$ & 27 \\
\hline Hydrolysis of $\mathrm{Zr}$ isopropylate & $447 \& 400 \&$ RT \& $250-600$ & calc. $\&$ vac. $+\mathrm{O}_{2} \& \mathrm{H}_{2} \mathrm{O}$ vapor $\&$ vac., $2 \mathrm{~h}$ & - & 38 \\
\hline Hydrolysis of $\mathrm{Zr}$ isopropylate & $397 \& 100-600$ & air \& vacuum, $2 \mathrm{~h}+\mathrm{O}_{2}$ & - & 8 \\
\hline Hydrolysis of $\mathrm{Zr}$ isopropylate & 397 \& e.g. 597 \& e.g. 597 & calc. \& vacuum, $2 \mathrm{~h} \& \mathrm{O}_{2}, 30 \mathrm{~min}$ & - & 51 \\
\hline \multirow[t]{2}{*}{ Hydrolysis of $\mathrm{Zr}$ isopropylate } & $597 \& 197-597$ & calc. \& vacuum & 78 & 39 \\
\hline & $997 \& 197-597$ & calc. \& vacuum & 10 & 39 \\
\hline Hydrolysis of $\mathrm{Zr}$ isopropylate & $600 / 800 / 900 \& 27-800$ & air, 3h \& vacuum & $55 / 35 / 20^{c}$ & 40 \\
\hline Hydrolysis of $\mathrm{Zr}$ isopropylate & $400 \& 400$ & calcination \& vacuum & 84 & 52 \\
\hline Hydrolysis of $\mathrm{Zr}$ propylate & 400 & $\mathrm{O}_{2} \&$ vacuum & $200-220$ & 53 \\
\hline Hydrolysis of $\mathrm{Zr}$ propylate & 400 & $\mathrm{O}_{2}, 1 \mathrm{~h} \& \mathrm{He} 30 \mathrm{~min}$ & 200 & 20 \\
\hline Hydrolysis of $\mathrm{Zr}$ propylate & 440 & $\mathrm{O}_{2}, 2 \mathrm{~h}$ & $200-220$ & 54 \\
\hline Hydrolysis of $\mathrm{Zr}$ propylate & 440 & air, $12 \mathrm{~h}$ & 120 & 55 \\
\hline Microemulsion from $\mathrm{ZrOCl}_{2}$ & $500-1200$ & annealing & $1.6-44.9$ & 31 \\
\hline $\mathrm{NH}_{3}$ hydrolysis of $\mathrm{ZrOCl}_{2}$ & $120 \& 400$ & drying \& preheating & - & 56 \\
\hline $\mathrm{NH}_{3}$ hydrolysis of $\mathrm{ZrOCl}_{2}$ & $550 \& 550$ & air, $2 \mathrm{~h} \& \mathrm{~N}_{2}, 7 \mathrm{~h}$ & 70 & 57 \\
\hline $\mathrm{NH}_{3}$ hydrolysis of $\mathrm{ZrOCl}_{2}$ & 550 & air, $1 \mathrm{~h}$ & 56 & 58 \\
\hline $\mathrm{NH}_{3}$ hydrolysis of $\mathrm{ZrOCl}_{2}$ & 500 & air, $6 \mathrm{~h}$ & 57 & 59,60 \\
\hline $\mathrm{NH}_{3}$ hydrolysis of $\mathrm{ZrOCl}_{2}$ & 600 & vacuum & 41 & 7 \\
\hline $\mathrm{NH}_{3}$ hydrolysis of $\mathrm{ZrOCl}_{2}$ & $100 \& 700$ & $\mathrm{O}_{2}, 5 \mathrm{~h}$ & 19 & 41 \\
\hline $\mathrm{NH}_{3}$ hydrolysis of dissolved $\mathrm{ZrCl}_{4}$ & $600-900$ & air, $2-6 h$ & $8.2-30$ & 45 \\
\hline $\mathrm{NH}_{3}$ hydrolysis of dissolved $\mathrm{ZrCl}_{4}$ & 600 & $\mathrm{O}_{2}$ & $30-36$ & 10 \\
\hline $\mathrm{NH}_{3}$ hydrolysis of $\mathrm{Zr}\left(\mathrm{NO}_{3}\right)_{4}$ & 500 & air, $2-3 \mathrm{~h}$ & $80^{\mathrm{b}}$ & 44 \\
\hline PICA process & 700 & air, $2 \mathrm{~h}$ & 33 & 34 \\
\hline $\mathrm{ZrO}\left(\mathrm{NO}_{3}\right)_{2}$ precipitation with hydrazine & $1450 \& 800$ & air \& vacuum & 1.0 & 32 \\
\hline A.D Mackay / nuclear grade & 500 & vacuum & 23.7 & 33,61 \\
\hline Alfa Aesar & $>1200 \& 800$ & air \& vacuum & 1.6 & 32 \\
\hline Alfa Aesar & 900 & air & 10.4 & 62 \\
\hline Alfa-Ventron & 620 & $\mathrm{O}_{2}, 0.5 \mathrm{~h} \& \mathrm{He}, 0.25 \mathrm{~h} \& \mathrm{H}_{2}, 0.5 \mathrm{~h}$ & $5.8^{\mathrm{c}}$ & 21 \\
\hline Alfa-Ventron & 500 & $\mathrm{O}_{2}$, overnight & $5.8^{\mathrm{d}}$ & 19 \\
\hline Criceram $/ \mathrm{ZrCl}_{4}+\mathrm{H}_{2} \mathrm{O}$ vapor & $877 / 903$ & air, $24 \mathrm{~h} / 30 \% \mathrm{O}_{2}+70 \% \mathrm{H}_{2} \mathrm{O}, 24 \mathrm{~h}$ & $6 / 4.2$ & 63 \\
\hline Daiichi Kigenso Kagaku Kogyo (RC100) & 400 & air, $15 \mathrm{~h}$ & 71 & 64 \\
\hline Degussa / flame hydrolysis & $600-800$ & air or vacuum & $37 \pm 1^{\mathrm{c}}$ & 65 \\
\hline Degussa & 450 & air, $4 \mathrm{~h}$ & 40 & 66 \\
\hline Gimex Technical Ceramics (RC-100) & $600 \& 400$ & $\mathrm{He}, 24 \mathrm{~h} \mathrm{\&} \mathrm{H}_{2}, 30 \mathrm{~min}$ & - & 23 \\
\hline Magnesium Elektron (E-10 powder) & - & vacuum & 14 & 24 \\
\hline MEL EC0100 & 580 & $\mathrm{O}_{2}, 2 \mathrm{~h}$ & 47 & 22,67 \\
\hline $\mathrm{MEL} \mathrm{Zr}(\mathrm{OH})_{4}$ & $\mathrm{RT} / 150 / 300 / 500$ & vacuum & $66.6-537$ & 68 \\
\hline $\mathrm{MEL} \mathrm{Zr}(\mathrm{OH})_{4}$ & $450 \& 600$ & air, $16 \mathrm{~h} \& \mathrm{O}_{2}$ /inert, $2 \mathrm{~h}$ & 90 & 28 \\
\hline Nanotek & - & - & 78 & 6 \\
\hline Saint-Gobain NorPro & - & - & 52 & 69 \\
\hline Commercial $\mathrm{Zr}(\mathrm{OH})_{4}$ & 700 & calcination, $6 \mathrm{~h}$ & 12 & 70 \\
\hline
\end{tabular}

This journal is $\odot$ The Royal Society of Chemistry [year] details about their zirconium oxide material.

Journal Name, 2010, [vol], 1-19 |3

b Surface area value reported prior to calcination.

c Surface area value reported prior to wafer pressing. 
seems to be a better reductant than molecular hydrogen. Based on the literature, the mechanism for oxygen removal remains unclear; is it removed as $\mathrm{O}_{2}$ or perhaps through dehydroxylation via multicoordinated $\mathrm{OH}$ groups, as shown in Eq. 1:

$$
\text { multi-OH }+ \text { multi-OH } \leftrightarrow \mathrm{O}_{\text {lattice }}+\text { vacancy }+\mathrm{H}_{2} \mathrm{O} .
$$

The presence of $\mathrm{Zr}^{3+}$ sites has been proposed based on electron paramagnetic resonance $(\mathrm{EPR})^{8,46,51,57}$. The $\mathrm{Zr}$ surface cations have been probed with $\mathrm{N}_{2} \mathrm{O}$, it decomposes on $\mathrm{Zr}^{3+}$ already at room temperature but also at higher temperatures, and reversibly adsorbs on $\mathrm{Zr}^{4+}$ sites ${ }^{6}$. Vacuum treatment at above $600^{\circ} \mathrm{C}$ is sufficient to initiate formation of oxygen vacancies ${ }^{81}$ and reduction of cations from $\mathrm{Zr}^{4+}$ to $\mathrm{Zr}^{3+6,81}$. Hydrogen treatment at $700^{\circ} \mathrm{C}$ also transforms some of the $\mathrm{Zr}^{4+}$ sites to $\mathrm{Zr}^{3+}$ sites ${ }^{81}$, but with hydrogen treatment at $600^{\circ} \mathrm{C}$, the amount of $\mathrm{Zr}^{3+}$ sites does not increase ${ }^{9}$ in agreement with the low reducibility with $\mathrm{H}_{2}$ mentioned previously. If the sample has been vacuum-activated at $400^{\circ} \mathrm{C}$, hydration quenches the defect centers $\left(\mathrm{Zr}^{3+}\right)$ and the defects have to be re-created with evacuation ${ }^{8}$. If the sample has been vacuum-activated at $800^{\circ} \mathrm{C}$, there are two options: (1) the defect centers are quenched but they are easier to re-create on a sintered surface, or (2) the defect centers are not quenched, rather coordinatively saturated with water and dehydration restores their coordinatively unsaturated state ${ }^{8}$. Based on EPR, the most exposed $\mathrm{Zr}^{3+}$ are transformed to $\mathrm{Zr}^{4+}$ when in contact with water $\left(200^{\circ} \mathrm{C}, 18\right.$ torr $\left.\mathrm{H}_{2} \mathrm{O}\right)$ but the others are coordinatively saturated with water and remaining $\mathrm{Zr}^{3+8}$.

Syzgantseva et al. have calculated the formation energies for oxygen vacancies, and based on those the zirconia (111) surface is less reducible than the (101) surface ${ }^{82}$, in line with the stability observation by Christensen and Carter ${ }^{4}$. When comparing to other oxides, the oxygen vacancy formation energy on the zirconia surface is $820-880 \mathrm{~kJ} / \mathrm{mol}$ and in the bulk $c a$. $860 \mathrm{~kJ} / \mathrm{mol}$, whereas those for titania, which is considered a reducible oxide, are $530-580 \mathrm{~kJ} / \mathrm{mol}$ on the surface and $670 \mathrm{~kJ} / \mathrm{mol}$ in the bulk ${ }^{82}$. Syzgantseva et al. have also predicted the conditions necessary to create oxygen vacancies with surface hydrogenation followed by desorption of water (temperature above $927^{\circ} \mathrm{C}$ and $\mathrm{H}_{2} \mathrm{O} / \mathrm{H}_{2}$ pressure ratio below $\left.10^{-5}\right)^{82}$. They conclude that water desorption takes place already at milder conditions, thus the simplifications in their computations required for, e.g., surface models might cause the discrepancy between theory and experiments ${ }^{82}$.

The oxygen mobility, dissociation and recombination on zirconia among other oxide materials were probed by Martin and Duprez ${ }^{66}$. Isotopic oxygen exchange experiments between ${ }^{16} \mathrm{O}_{2}$ and ${ }^{18} \mathrm{O}_{2}$ showed surface oxygen exchange at $380-780^{\circ} \mathrm{C}^{66}$. The maximum $\mathrm{O}$-exchange rate was at $530{ }^{\circ} \mathrm{C}$ and the exchange rate was further expedited in the presence of $\mathrm{Rh}$ or Pt on the surface ${ }^{66}$. The exchange is attributed to c.u.s. $\mathrm{Zr}^{3+}$ centers created by vacuum thermal treatment and their ability to dissociate molecular oxygen ${ }^{66}$. The number of exchanged oxygens on $\mathrm{ZrO}_{2}$ was found to be greater than the theoretical number of surface oxygen species implying that bulk oxygen atoms participated in the exchange ${ }^{66}$.

\section{Hydroxyl species and the interaction of water and hydrogen on monoclinic zirconia}

Dissociative adsorption of water on monoclinic zirconia is exothermic, occurring already at room temperature ${ }^{31,69}$. Therefore the surfaces of zirconia are hydroxylated under ambient and in most reactive atmospheres. In this section, different types of $\mathrm{OH}$ groups are discussed, followed by methods of manipulating the hydroxyl species on the surface of zirconia.

\subsection{Nature, density and probing of hydroxyl species}

Typical hydroxyl sites reported on monoclinic zirconia include terminal $\mathrm{OH}$ groups (also known as monocoordinated $\mathrm{OH}$ ) and tribridged $\mathrm{OH}$ groups, first assigned by Tsyganenko and Filimonov as a part of a wider study on different oxides including cerium, hafnium, magnesium, nickel, cobalt and several other oxides ${ }^{3,71}$. Schematic drawings of the hydroxyl groups are presented in Fig. 2. The latter species has been assigned either tribridged ${ }^{7,25,70,71}$, bibridged ${ }^{29,53,61,63}$ or simply presumed as multicoordinated $\mathrm{OH}$ groups ${ }^{18,19,23,59}$. In this work, the term multicoordinated is generally used to refer to this species.
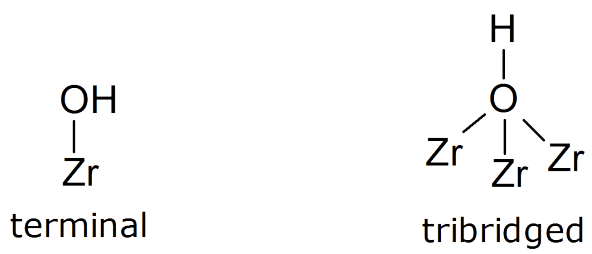

Fig. 2 Terminal and tribridged hydroxyl species.

The terminal and multicoordinated hydroxyl species are usually observed in IR spectroscopy at $3780-3760 \mathrm{~cm}^{-1}$ and $3690-3650 \mathrm{~cm}^{-1}$, respectively ${ }^{7,19,50,61,71}$, as shown in Table 2 and Figure 3. Jacob et al. assign the bands to $\mathrm{OH}$ groups related to trigonally coordinated $\mathrm{O}^{2-}$ anions ( $c a$. $3774 \mathrm{~cm}^{-1}$ ) and to tetrahedrally coordinated $\mathrm{O}^{2-}$ anions ( $c a$. $\left.3668 \mathrm{~cm}^{-1}\right)^{65}$, however, without further evidence. Yamaguchi et al. suggested that the bands at $3780 \mathrm{~cm}^{-1}$ and $3680 \mathrm{~cm}^{-1}$ would be isolated hydroxyls (as opposed to hydrogen-bonded ones) of bridged and terminal type adapting the interpretation for rutile, a type of $\mathrm{TiO}_{2}{ }^{59}$. The occurrence of a band at $3740-3720 \mathrm{~cm}^{-1}$ is typically interpreted as a sign of tetragonal phase and its bibridged hydroxyl. Yet the band of terminal $\mathrm{OH}$ (typically at $3780-3760 \mathrm{~cm}^{-1}$ ) shifts towards lower 
wavenumbers (even down to $3680 \mathrm{~cm}^{-1}$ ) with increasing degree of hydration due to hydrogen bonding ${ }^{18}$ and at that point the multicoordinated $\mathrm{OH}$ band is even below $3600 \mathrm{~cm}^{-140}$, as suggested already by Tret'yakov et al. ${ }^{44}$. Thus interpreting the hydroxyl band position must be done carefully, considering the possibility of hydrogen bonding at higher degrees of hydration. Tsyganenko and Filimonov also report an IR band at $3380 \mathrm{~cm}^{-1}$, assigned to hydrogen-bonded hydroxyl groups $^{3,71}$. Unresolved broad bands at $3600-2800 \mathrm{~cm}^{-1}$ are assigned to hydrogen-bonded polynuclear water species ${ }^{61}$ based on the IR spectra of hydrogen bonding of water ${ }^{83}$. The hydrogen bonding is suggested to occur between molecularly adsorbed water and the hydroxyl groups ${ }^{18,33,42,53}$.The $\mathrm{OH}$ wavenumber and thermal stability depend on the crystalline phase of zirconia ${ }^{9}$; thus impurities in the crystalline phase can lead to misinterpretations.

Table 2 Experimentally and theoretically determined $v(\mathrm{OH})$ wavenumbers

\begin{tabular}{|c|c|c|c|c|}
\hline $\begin{array}{l}\text { Terminal } \\
\mathrm{cm}^{-1}\end{array}$ & $\begin{array}{l}\text { Bibridged } \\
\mathrm{cm}^{-1}\end{array}$ & $\begin{array}{l}\text { Tribridged } \\
\mathrm{cm}^{-1}\end{array}$ & $\begin{array}{l}\text { H-bonded } \\
\mathrm{cm}^{-1}\end{array}$ & Ref. \\
\hline \multicolumn{5}{|c|}{ Experimental } \\
\hline 3770 & & 3670 & 3380 & 3,71 \\
\hline 3776 & & 3667 & & 50 \\
\hline 3772 & & $3681 \& 3660$ & & 7 \\
\hline 3775 & & $3675-3668$ & $3600-2800$ & 27 \\
\hline$\approx 3775$ & & $3695-3662$ & $<3600$ & 40 \\
\hline 3778 & & $3680-3675$ & $3455-3450$ & 63 \\
\hline $3779-3771$ & $3738-3727$ & $3682-3660$ & $\approx 3400$ & 29 \\
\hline 3740 & & 3675 & & 19 \\
\hline 3760 & & 3660 & $3600-2800$ & 61 \\
\hline 3770 & & 3680 & & 53 \\
\hline 3769 & & & & 24 \\
\hline 3774 & & 3668 & & 65,81 \\
\hline \multicolumn{5}{|c|}{ Theoretical } \\
\hline $3822-3743$ & $3755-3568$ & $3647-3498$ & & 67 \\
\hline \multirow[t]{2}{*}{3778} & 3550 & 3475 & & 84 \\
\hline & 3750 & 3700 & & 74 \\
\hline
\end{tabular}

Terminal hydroxyls are bound directly to a single cation at oxygen lattice sites whereas the multicoordinated hydroxyls are located at low-index faces ${ }^{61}$. The former are able to accommodate a water molecule to hydrogen-bond on an edge or a corner site of the oxide particle while the latter are incapable of hydrogen bonding due to steric factors ${ }^{61}$. The assignment of multicoordinated hydroxyls to low-index faces ${ }^{61}$ and the observed decrease in the relative amount of terminal $\mathrm{OH}$ species with vacuum treatment at $500-1000{ }^{\circ} \mathrm{C}^{65}$ are in line with the observation that the regularity of sintered crystals is higher ${ }^{39}$.

Based on IR spectroscopy, the tribridged $\mathrm{OH}$ species (at $3690-3681 \mathrm{~cm}^{-1}$ and at $3670-3660 \mathrm{~cm}^{-1}$ ) on zirconia are

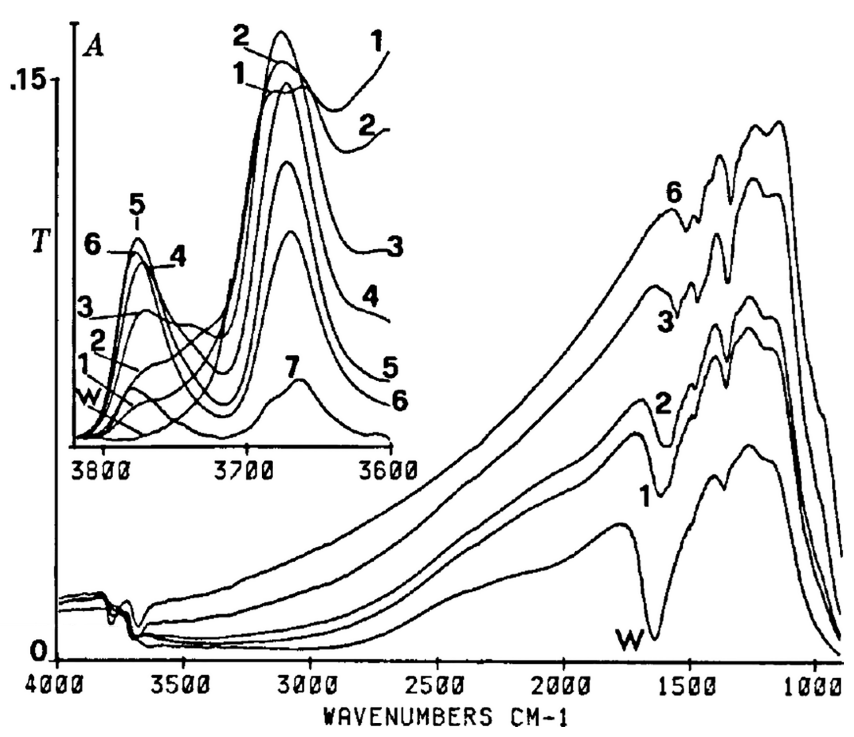

Fig. 3 The evolution of hydroxyl species with activation after rehydration. Activation conditions: W: Rehydrated sample still in 4 torr $\mathrm{H}_{2} \mathrm{O}, 1: 27^{\circ} \mathrm{C}, 5 \mathrm{~min}, 2: 27^{\circ} \mathrm{C}, 30 \mathrm{~min}, 3: 137^{\circ} \mathrm{C}, 30 \mathrm{~min}, 4$ : $247^{\circ} \mathrm{C}, 5: 327^{\circ} \mathrm{C}, 6: 397^{\circ} \mathrm{C}, 7: 497^{\circ} \mathrm{C}$. Reproduced from ref. ${ }^{18}$ with permission. Copyright 1988, Elsevier.

suggested to be actually two species ${ }^{7,40}$, and signs of multiple tribridged species are also seen both at high ${ }^{18,28}$ and low ${ }^{18}$ degrees of hydration. The $\mathrm{OH}$ species differ slightly in their acidic character ${ }^{40}$ and their behavior with calcination at $600-900^{\circ} \mathrm{C}$ suggests that the low-frequency band $\left(3670-3660 \mathrm{~cm}^{-1}\right)$ should be assigned to tribridged species at crystallographic defects selectively annealed during sintering ${ }^{40}$. However, in our recent investigations for reduced zirconia with no visible $\mathrm{H}$-bonding effect, both terminal and multicoordinated bands shift down in wavenumber with increasing temperature ${ }^{28}$.

The nature of the multicoordinated $\mathrm{OH}$ species has also been considered at the atomic level. The $\mathrm{ZrO}_{2}(111)$ surface is suggested to have too small a distance between the c.u.s. $\mathrm{O}^{2-}$ and the c.u.s. $\mathrm{Zr}^{4+}$ site (only $\left.2 \AA\right)^{40}$, that is not enough space to dissociate a water molecule to form terminal and bibridged $\mathrm{OH}$ groups. The corresponding distance between $\mathrm{Zr}^{4+}$ and tribridged oxygen is $\approx 2.3 \AA$, allowing formation of a terminal and a tribridged hydroxyl via dissociation ${ }^{40}$. Based on theory, both bibridged and tribridged species exist ${ }^{67,74}$, Korhonen et $a l$. report that at low coverages $(\theta=0.25 \mathrm{ML})$, there are only bibridged hydroxyls on the (111) and (101) surfaces ${ }^{67}$. Bibridged hydroxyls are also claimed to form following dissociative adsorption on the (001) surface until a full coverage $(\theta=1 \mathrm{ML})$ is obtained ${ }^{85}$.

The hydroxyl IR vibrations have been determined computationally ${ }^{67,74,84}$ as shown in Table 2. It demonstrates the large variation of calculated frequencies which span, e.g., over 200 
wavenumbers for tribridged $\mathrm{OH}$ species. Diversity of calculated frequencies for adsorbed $\mathrm{OH}$ is not unique to $\mathrm{ZrO}_{2}$ but also reported on $\mathrm{CeO}_{2}{ }^{86}$. The overall discrepancy between calculated and experimental frequencies can follow from three different origins. First, frequencies are typically calculated using a so-called harmonic approximation, which specifically leaves out possible anharmonic effects leading, in part, to errors in calculated frequencies. Secondly, discrepancies can also originate from the inability of density functional theory (DFT) to reliably describe the electronic structure of a given system. Thirdly, for polycrystalline oxide nanostructures, the discrepancy of calculated frequencies compared to the experimental ones can stem from the fact that an active surface site cannot experimentally be identified definitely. This may lead to an inaccurate computational adsorption site model, which differs from the real adsorption site. Moreover, the application of a cluster model to simulate $\mathrm{ZrO}_{2}$ surfaces can impact on the calculated frequencies.

Hydroxyl densities can be estimated based on the amount of water removed from zirconia ${ }^{34}$, water adsorbed on zirconia $^{27,69}$, or on quantification via ${ }^{1} \mathrm{H}$ MAS NMR ${ }^{68}$, and these estimates are presented in Table 3. In the table, the scaled values represent $\mathrm{OH}$ density regardless whether it has been measured directly or by water adsorption (each water molecule is assumed to form two surface hydroxyls).

The observed amount of adsorbed water decreases with increasing temperature, as expected. Based on an estimated number of $\mathrm{Zr}$ atoms on the $\mathrm{ZrO}_{2}$ surface ( $c a .12 \mu \mathrm{mol} / \mathrm{m}^{2}$ ) and water adsorption leading to formation of two $\mathrm{OH}$ groups, one on $\mathrm{Zr}$ cation and one on a surface oxygen, the estimated hydroxyl densities seem reasonable in magnitude. Nawrocki et al. report a theoretical maximum $\mathrm{OH}$ concentration of $c a$. $25 \mu \mathrm{mol} / \mathrm{m}^{2}$ based on the average surface $\mathrm{Zr}$ concentration of $c a$. $12.2 \mu \mathrm{mol} / \mathrm{m}^{237}$. The amount of induced hydroxyls $\left(20.2 \mu \mathrm{mol} / \mathrm{m}^{2} \text { desorbed above } 200^{\circ} \mathrm{C}\right)^{34}$ seems to be in agreement with the estimated total $\mathrm{OH}$ capacity, also Piskorz et al. ${ }^{77}$ have reported similar theoretical $\mathrm{OH}$ site densities.

The energetics of water adsorption have been investigated both with an experimental and a theoretical approach. Piskorz et al. have studied the effect of surface hydration on the stability of the crystal planes using DFT calculations ${ }^{77}$. A hydroxylated surface is favored over the clean surface on very small crystallites $(<20 \AA)$, whereas hydration does not enhance the stability of the surface on crystallites between $500 \AA$ and $2000 \AA$, and the authors claim that the transformation from clean to hydrated surface is attenuated ${ }^{77}$. However, this is not in line with experimental observations suggesting the hydroxylated surface to be the prevalent one. Based on microcalorimetry, the integral enthalpy of adsorption for a half-layer coverage of water $\left(3.65 \mu \mathrm{mol} / \mathrm{m}^{2}\right)$ is $-142 \mathrm{~kJ} / \mathrm{mol}$ on monoclinic $\mathrm{ZrO}_{2}$ nanoparticles (crystal size $100-500 \AA$, specific surface area $\left.1.6-27.2 \mathrm{~m}^{2} / \mathrm{g}\right)^{31}$. This is in agreement with the values measured for powder zirconias $\left(1.0-1.6 \mathrm{~m}^{2} / \mathrm{g}\right)^{32}$ giving a range from $-110 \mathrm{~kJ} / \mathrm{mol}$ to $-170 \mathrm{~kJ} / \mathrm{mol}$. Theoretical adsorption energy values typically range from $-80 \mathrm{~kJ} / \mathrm{mol}$ to $-190 \mathrm{~kJ} / \mathrm{mol}$ on (001), (111), (111), and $(\overline{1} 01)^{67,69,85}$. We have recently reported dissociative adsorption energies for the first adsorbing water molecule ranging from $-106 \ldots-119 \mathrm{~kJ} / \mathrm{mol}$ up to $-297 \mathrm{~kJ} / \mathrm{mol}$, for flat, stepped and corner adsorption sites ${ }^{28}$. The calculated values demonstrate the structure sensitivity of dissociative adsorption of water, which is clearly most favorable on a c.u.s. site such as a corner site suggested by our DFT calculations ${ }^{28}$.

\subsection{Manipulation of hydroxyl species}

The intensity ratio of terminal and multicoordinated hydroxyls varies according to temperature, used atmosphere and pretreatment. Hydroxyl species can be added to the surface with water or hydrogen treatments and removed using heat together with inert gas or evacuation. The initial state of zirconia can usually be restored with evacuation or flushing with inert at the same temperature as before rehydration ${ }^{28,53}$.

Sample hydration is typically carried out by adsorbing water vapor, either by letting the sample adsorb moisture from air (virgin material in ${ }^{18}$ ), equilibrating in a closed vessel with water vapor in nitrogen (to avoid $\mathrm{CO}_{2}$ adsorption) ${ }^{34}$, or by feeding water vapor to the sample $18,23,28,58,65$. The rehydrated sample can be used as such or after further dehydration with vacuum and/or elevated temperature (e.g. $\left.{ }^{18,65}\right)$. Rehydration has also been carried out by exposing the sample to hydrogen at room temperature ${ }^{53}$ or by contacting the zirconia sample with water-saturated hydrogen for $10 \mathrm{~min}$ at $50^{\circ} \mathrm{C}^{42}$. Unfortunately, rehydration is often described vaguely, omitting time, water vapor concentration or temperature, all relevant in controlling the degree of hydroxylation.

Commonly used methods for dehydration are vacuuming $^{20,24,33,70}$ or flushing ${ }^{67}$ at elevated temperatures. Undissociated water adsorbed at room temperature is completely removed in vacuum by $127^{\circ} \mathrm{C}^{27}$ and after evacuation at $200^{\circ} \mathrm{C}$ only two distinct $\mathrm{OH}$ bands at $c a .3775 \mathrm{~cm}^{-1}$ and $3665 \mathrm{~cm}^{-1}$ remain ${ }^{40}$. Köck et al. pretreated the zirconia in air at $900^{\circ} \mathrm{C}$ to completely dehydroxylate the sample, and only very weak $\mathrm{OH}$ bands remained ${ }^{62}$. Evacuation at $500^{\circ} \mathrm{C}$ is reported to be insufficient for complete dehydroxylation ${ }^{20}$, but already at $550^{\circ} \mathrm{C}$ spectra with no trace of surface hydroxyls after evacuation are shown ${ }^{53}$. The conditions necessary for total $\mathrm{OH}$ removal are at $c a .550-750^{\circ} \mathrm{C}$ in vacuo ${ }^{18,44,65}$, in agreement with the enthalpies for water adsorption discussed earlier in this paper in Section 3.1. As most pretreatments and processes do not reach these conditions, the presence of these $\mathrm{OH}$ groups on the zirconia surface in process conditions is practically inevitable, especially in biomass-based processes, where water is present. 
Table 3 Hydroxyl densities reported in literature

\begin{tabular}{|c|c|c|c|}
\hline Measurement & As reported & Scaled to $\mu \mathrm{mol} \mathrm{OH} / \mathrm{m}^{2}$ & Ref. \\
\hline$\overline{\mathrm{OH}}$ concentration $\left(S A=19 \mathrm{~m}^{2} / \mathrm{g}\right)$ & $6.2 \mathrm{OH} / \mathrm{nm}^{2}$ & 10.30 & 25 \\
\hline $\mathrm{OH}$ concentration $\left(S A=110 \mathrm{~m}^{2} / \mathrm{g}\right)$ & $9.4 \mathrm{OH} / \mathrm{nm}^{2}$ & 15.61 & 25 \\
\hline Induced hydroxyls (desorbed above $200^{\circ} \mathrm{C}$ ) after $48 \mathrm{~h}$ in humid $\mathrm{N}_{2}$ at RT & $20.2 \mu \mathrm{mol} \mathrm{OH} / \mathrm{m}^{2}$ & 20.2 & 34 \\
\hline $\mathrm{OH}$ coverage calc. from $\mathrm{H}_{2}$ evolution after standardization $\left(400^{\circ} \mathrm{C}, \mathrm{O}_{2}, 1 \mathrm{~h}\right)$ & $2.1 \cdot 10^{13} \mathrm{OH} / \mathrm{cm}^{2}$ & 0.35 & 20 \\
\hline Estimated full $\mathrm{OH}$ coverage before standardization & $7.2 \cdot 10^{13} \mathrm{OH} / \mathrm{cm}^{2}$ & 1.2 & 20 \\
\hline Estimated chemisorption capacity at $25^{\circ} \mathrm{C}$ & $5.7 \mathrm{mg} \mathrm{H}_{2} \mathrm{O} / \mathrm{g}$ & 26.7 & 33 \\
\hline Irreversibly adsorbed water at $25^{\circ} \mathrm{C}$ & $4.8 \mathrm{mg} \mathrm{H}_{2} \mathrm{O} / \mathrm{g}$ & 22.5 & 33 \\
\hline Surface hydrogen after $\mathrm{H}_{2} \mathrm{O}$ adsorption at $200^{\circ} \mathrm{C}$ & $4.20 \mathrm{H} / \mathrm{nm}^{2}$ & 6.97 & 69 \\
\hline Surface hydrogen after $\mathrm{H}_{2} \mathrm{O}$ adsorption at $300^{\circ} \mathrm{C}$ & $3.62 \mathrm{H} / \mathrm{nm}^{2}$ & 6.01 & 69 \\
\hline Surface hydrogen after $\mathrm{H}_{2} \mathrm{O}$ adsorption at $400^{\circ} \mathrm{C}$ & $3.22 \mathrm{H} / \mathrm{nm}^{2}$ & 5.51 & 69 \\
\hline Full coverage of water ( $2 x$ half-layer coverage) & $4.4 \mathrm{H}_{2} \mathrm{O} / \mathrm{nm}^{2}$ & 14.6 & 31 \\
\hline Theoretical $\mathrm{H}_{2} \mathrm{O}$ adsorption capacity at $\theta=1 \mathrm{ML}$ on (111) surface & $8.9 \mathrm{H}_{2} \mathrm{O} / \mathrm{nm}^{2}$ & 29.6 & 77 \\
\hline Theoretical $\mathrm{H}_{2} \mathrm{O}$ adsorption capacity at $\theta=1 \mathrm{ML}$ on (111) surface & $7.1 \mathrm{H}_{2} \mathrm{O} / \mathrm{nm}^{2}$ & 23.6 & 77 \\
\hline Theoretical $\mathrm{H}_{2} \mathrm{O}$ adsorption capacity at $\theta=1 \mathrm{ML}$ on (011) surface & $5.2 \mathrm{H}_{2} \mathrm{O} / \mathrm{nm}^{2}$ & 17.3 & 77 \\
\hline Theoretical $\mathrm{H}_{2} \mathrm{O}$ adsorption capacity at $\theta=1 \mathrm{ML}$ on (001) surface & $7.5 \mathrm{H}_{2} \mathrm{O} / \mathrm{nm}^{2}$ & 24.9 & 77 \\
\hline
\end{tabular}

The partial dehydration method ${ }^{18,44,53,65}$ can be used to vary the concentration of several types of $\mathrm{OH}$ groups on zirconia. Depending whether the amount of adsorbed water results from dehydration or rehydration, the surface species distribution might be different as demonstrated by Bolis et al. ${ }^{27}$ by heating the sample in a closed vessel and analyzing the $\mathrm{OH}$ distribution on the sample before and after. Based on their findings, dehydration is systematic even in terms of the surface effects whereas rehydration is more blotchy as the water collides and dissociates on the surface as hydrogen-bonded pairs $^{27}$. Thus allowing the system to approach equilibrium leads to a more even surface distribution. All in all, the method chosen to adjust the amount of hydroxyls influences their distribution on the zirconia surface.

Cerrato et al. suggest based on theory that water dissociates forming a tribridged $\mathrm{OH}$ at a tricoordinated c.u.s. oxygen and a terminal $\mathrm{OH}$ on a c.u.s. cation, leaving a c.u.s. monocoordinated oxygen in the same sphere unsaturated ${ }^{40}$. The presence of the suggested c.u.s. monocoordinated oxygen is in agreement with $\mathrm{CO}_{2}$ adsorption experiments on a fully hydrated surface, yielding monodentate and bidentate carbonate species requiring the presence of basic, c.u.s. oxygen ions ${ }^{40}$.

Based on theory, dissociative adsorption for the first adsorbed water molecule of a unit cell $(\theta=0 \ldots 0.25 \mathrm{ML})$ has been reported on $(\overline{1} 11)^{67,77},(\overline{101})^{67}$, and $(111)^{77}$ surfaces. The second $\mathrm{H}_{2} \mathrm{O}$ molecule adsorbs molecularly on $(\overline{1} 11)^{67,77}$ and $(111)^{77}$, and dissociatively on $(\overline{101})^{67}$ surfaces. The additional $\mathrm{H}_{2} \mathrm{O}$ molecules adsorb molecularly ${ }^{67,77}$. For both (111) and (101) surfaces already the first water molecule forming two hydroxyls is hydrogen-bonded ${ }^{67}$. Iskandarova et al. have reported both dissociative and molecular adsorption enthalpies resulting in coverages of $0.5 \mathrm{ML}$ and $1 \mathrm{ML}$ on a (001) surface, the dissociative adsorption is favored by $45-75 \mathrm{~kJ} / \mathrm{mol}$ in both cases ${ }^{85}$. Our recent investigations suggest that at $\theta=0.25 \mathrm{ML}$, there is hydrogen bonding between the hydroxyl groups on the (111) surface but not on the hydroxylated $(\overline{2} 12)$ edge and corner sites ${ }^{28}$. Cerrato et al. point out that the hydrogen bonding at high hydroxyl coverages only takes place between $\mathrm{OH}$ species and coordinated undissociated water whereas hydrogen bonding between $\mathrm{OH}$ pairs is unlikely $^{40}$.

Morterra et al. hypothesize that if all surface oxygens on a (111) surface are transformed into hydroxyls to maintain electrical neutrality, and then dehydration takes place via desorbing terminal hydroxyls and hydrogen atoms from bridging $\mathrm{OH}$ groups (shown in Fig. 4), only bridging oxygens are left behind, and thus highly uncoordinated $\mathrm{Zr}^{4+}$ sites are achieved $^{39}$. The intensity of the terminal hydroxyl species decreases more than that of the multicoordinated $\mathrm{OH}$ when the zirconia sample is thermoevacuated at $500-600^{\circ} \mathrm{C}$ after calcination at $600^{\circ} \mathrm{C}^{70}$. Dehydration in vacuum at $500-1000^{\circ} \mathrm{C}$ followed by hydration caused the relative amount of terminal $\mathrm{OH}$ to decrease significantly compared to multicoordinated $\mathrm{OH}$, whereas oxygen treatment $\left(500-750^{\circ} \mathrm{C}\right)$ before hydration had the opposite effect ${ }^{65}$. The decrease in terminal hydroxyls with high-temperature vacuum treatment is assigned to increasing amount of tetragonal zirconia, as the tetragonal phase is stabilized by oxygen vacancies ${ }^{65}$.

One approach to hydroxyl studies is to replace hydrogen with its heavier isotope deuterium using $\mathrm{D}_{2}$ or $\mathrm{D}_{2} \mathrm{O}$, or to replace ${ }^{16} \mathrm{O}$ with ${ }^{18} \mathrm{O}$, all of which are easily observable in both IR and mass spectrometry. OD groups, known as deuteroxyls, have been investigated by many groups $19,21,24,42,44,56,59,61,87$ while oxygen-labeling studies are more scarce ${ }^{66,69,81}$.

Observed deuteroxyl IR wavenumbers are collected in Table 4. Erkelens et al. report that the ratios of the frequen- 

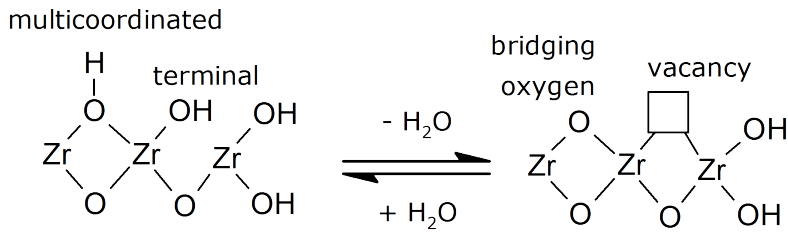

Fig. 4 (De)hydroxylation mechanism.

cies between the $\mathrm{OH}$ bands $\left(3732 \mathrm{~cm}^{-1}, 3660 \mathrm{~cm}^{-1}\right.$, and $\left.3584 \mathrm{~cm}^{-1}\right)$ and the OD bands $\left(2758 \mathrm{~cm}^{-1}, 2702 \mathrm{~cm}^{-1}\right.$, and $2651 \mathrm{~cm}^{-1}$ ) are $c a$. 1.36, in agreement with the expected isotopic substitution ${ }^{56}$. Similar results with additional $\mathrm{OH}$ band at $3738-3727 \mathrm{~cm}^{-1}$ (OD at $2757-2748 \mathrm{~cm}^{-1}$ ) were reported also by Guglielminotti ${ }^{29}$. A spectrum showing the changes in OH/OD groups is shown in Fig. 5.

Table 4 Experimentally determined $v(\mathrm{OD})$ wavenumbers

\begin{tabular}{llll}
\hline $\begin{array}{l}\text { Terminal } \\
\mathrm{cm}^{-1}\end{array}$ & $\begin{array}{l}\text { Multicoordinated } \\
\mathrm{cm}^{-1}\end{array}$ & $\begin{array}{l}\text { Other } \\
\mathrm{cm}^{-1}\end{array}$ & Ref. \\
\hline 2780 & 2703 & & 44 \\
2758 & 2702 & 2651 & 56 \\
2770 & 2695 & & 61 \\
$2785-2779$ & $2713-2701$ & $2757-2748$ & 29 \\
2780 & 2710 & & 59 \\
2783 & $2713-2710$ & & 63 \\
2760 & 2706 & & 48 \\
2760 & 2710 & & 19 \\
2782 & 2705 & & 81 \\
\hline
\end{tabular}

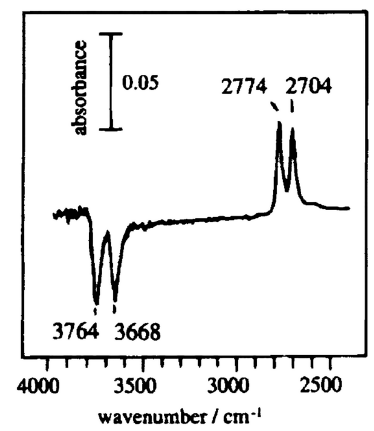

Fig. 5 Difference spectra of OH/OD species before and after $30 \mathrm{~min}$ in 100 torr $\mathrm{D}_{2}$ at $150^{\circ} \mathrm{C}$. Reproduced from ref. ${ }^{87}$.

Repeated treatments with, e.g., 10 torr of $\mathrm{D}_{2} \mathrm{O}$ vapor ${ }^{44}$ at room temperature almost completely replace hydrogen with deuterium in both terminal and multicoordinated $\mathrm{OH}$, resulting in corresponding OD groups $19,24,44,56,59,61$. The terminal species seem to exchange more easily than the multicoordinated species ${ }^{24,59}$.

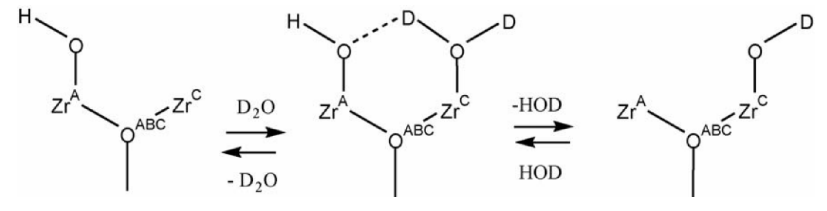

Fig. 6 The OD exchange mechanism proposed by Ignatchenko et $a l .{ }^{69}$. Reproduced from ref. ${ }^{69}$ with permission. Copyright 2006,

Elsevier.

Ignatchenko et al. propose that the hydrogen-deuterium exchange mechanism would proceed via hydroxyl/deuteroxyl exchange so that a deuterated water adsorbs adjacent to an existing terminal hydroxyl species and a hydrogen bond is formed between the $\mathrm{D}_{2} \mathrm{O}$ and the $\mathrm{OH}$ species ${ }^{69}$. Then the hydrogen-bonding deuterium atom and the original $\mathrm{OH}$ group desorb as HDO species, leaving the OD species on the surface. The mechanism is shown in Fig. 6.

Labeling the oxygen of water $\left(\mathrm{H}_{2}^{18} \mathrm{O}\right)$ reveals that the oxygens of hydroxyls are thoroughly exchanged by $400^{\circ} \mathrm{C}$, yet at $200^{\circ} \mathrm{C}$ the findings of Ignatchenko et al. ${ }^{69}$ disagree with the suggested mechanism in Fig. 6. It appears that already at $200^{\circ} \mathrm{C}$ the terminal hydroxyls can be exchanged but for the multicoordinated ones higher temperatures (closer to $400^{\circ} \mathrm{C}$ ) are required ${ }^{69}$, and the presented mechanism should be modified to also apply for the multicoordinated hydroxyls. Based on these findings, it seems that the hydrogen scrambling follows the suggested mechanism ${ }^{69}$ (see Fig. 6). The terminal $\mathrm{OH}$ species are completely exchanged via the normal (de)hydroxylation mechanism involving also multicoordinated $\mathrm{OH}$ groups and labeled $\mathrm{H}_{2}^{18} \mathrm{O}$ as deduced from the applied temperature range $\left(200-400^{\circ} \mathrm{C}\right)$. The exchange of multicoordinated hydroxyls requires a new mechanism hypothesis and we propose that multi-OH groups are removed as water, leaving behind one oxygen atom and an oxygen vacancy (see Eq. 1). This mechanism may be predominating only at high temperatures when terminal $\mathrm{OH}$ species have already been desorbed.

In addition to water or its deuterated counterpart, also $\mathrm{H}_{2}$ or $\mathrm{D}_{2}$ can be used to create surface $\mathrm{OH}$ or OD groups on monoclinic zirconia. He and Ekerdt have suggested that gas-phase hydrogen is able to replenish $\mathrm{OH}$ groups ${ }^{21}$, the hydroxyl IR bands emerge at $200-600^{\circ} \mathrm{C}^{9,48,53}$ for both terminal and multicoordinated hydroxyl species ${ }^{53}$.

Hydroxyl formation mechanism by molecular hydrogen can be either homolytic, resulting in two hydroxyl species and two electrons ${ }^{9}$, or heterolytic, resulting in IR-inactive $\mathrm{Zr}-\mathrm{H}\left(\mathrm{H}^{+}\right.$ type) species and a hydroxyl $(\mathrm{OH})$ species $^{49}$. At temperatures above $100^{\circ} \mathrm{C}$, large amounts of hydroxyl species are formed likely due to homolytic dissociation of hydrogen ${ }^{48}$, whereas hydrogen contact at room temperature induces heterolytic dissociation ${ }^{48}$. Heterolytic dissociative adsorption of $\mathrm{H}_{2}$ at room 
temperature seems to require unhydroxylated c.u.s. $\mathrm{Zr}$ sites, as pretreatment above $600^{\circ} \mathrm{C}$ is necessary to remove adsorbed water from the zirconia surface ${ }^{26,49}$. Even though Bianchi et al. have observed increasing hydroxyl species intensities in IR during $\mathrm{H}_{2}$ treatment, they report no adsorption or desorption of hydrogen at $25-400^{\circ} \mathrm{C}$, and no water evolution during $\mathrm{H}_{2}$-TPR from $25^{\circ} \mathrm{C}$ up to $700^{\circ} \mathrm{C}^{53}$. Assuming no redox process concerning the $\mathrm{Zr}$ cations, a hydrogen desorption mechanism is postulated for $\mathrm{Zr}-\mathrm{H}$ and $\mathrm{Zr}-\mathrm{OH}$ sites leading to $\mathrm{Zr}$ and $\mathrm{Zr}-\mathrm{O}$ sites, as hydrogen adsorbed at $550^{\circ} \mathrm{C}$ is desorbed from $\mathrm{m}-\mathrm{ZrO}_{2}$ at $600^{\circ} \mathrm{C}^{9}$.

According to Syzgantseva et al., hydrogen dissociates on $\mathrm{Zr}^{3+}$ with a neighboring oxygen vacancy $\left(v_{o}\right)$, leading to formation of $\mathrm{Zr}-\mathrm{H}$ hydrides and the transformation of $\mathrm{Zr}$ cations into $\mathrm{Zr}^{4+}$ species ${ }^{82}$. The proposed mechanism is presented in Fig. 7. Addition of gas-phase oxygen to the $\mathrm{Zr}-\mathrm{H}$ hydrides, produced by gas-phase $\mathrm{H}_{2}$ at room temperature, increases the $\mathrm{OH}$ intensity at $3668 \mathrm{~cm}^{-1}$ (generally considered as multicoordinated $\mathrm{OH}$ ), creates the $3774 \mathrm{~cm}^{-1} \mathrm{OH}$ band (terminal $\mathrm{OH}$ ) and decreases the intensity of the $\mathrm{Zr}-\mathrm{H}$ species at $1565 \mathrm{~cm}^{-181}$. Substituting regular oxygen $\left({ }^{16} \mathrm{O}_{2}\right)$ with isotopically labeled oxygen $\left({ }^{18} \mathrm{O}_{2}\right)$ does not affect the position of the $\mathrm{OH}$ bands (expected shift $11 \mathrm{~cm}^{-1}$ ), thus the $\mathrm{OH}$ formation seems to occur on lattice oxygen rather than the gas-phase originating oxygen species ${ }^{81}$.

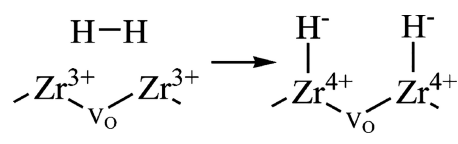

Fig. 7 The hydrogen dissociation mechanism proposed by Syzgantseva et al. ${ }^{82}$. Reproduced from ref. ${ }^{82}$ with permission. Copyright 2012, American Chemical Society.

Treatment with deuterium gas at $200^{\circ} \mathrm{C}(1 \mathrm{~h}, 18$ torr) and $250^{\circ} \mathrm{C}(1 \mathrm{~h}, 250$ torr $)$, is sufficient to exchange virtually all hydrogen of hydroxyl groups to deuterium ${ }^{56}$. He and Ekerdt report that the deuterium in OD groups is replaced by hydrogen already at $200^{\circ} \mathrm{C}$ with hydrogen dissociating on the zirconia surface ${ }^{19}$. At $150^{\circ} \mathrm{C}$ in $488 \mathrm{kPa}$ of $\mathrm{D}_{2}$, half of the hydrogen in surface $\mathrm{OH}$ species are changed to deuterium within $30 \mathrm{sec}-$ onds ${ }^{42}$. The H/D exchange takes place already at $100^{\circ} \mathrm{C}$ with $\mathrm{D}_{2}$ in the gas phase, however, at $200^{\circ} \mathrm{C}$ the exchange rate increases considerably ${ }^{26}$. The activation energies of the H/D exchange reaction with $\mathrm{D}_{2}$ are similar for both terminal and multicoordinated hydroxyls, and they seem to increase with the progress of the reaction ${ }^{26}$. This is interpreted to be due to the overall exchange (migration and replacement of atomic hydrogen by deuterium) being limited by $\mathrm{D}$ migration on the surface, subject to heterogeneity of potential barriers to various sites $^{26}$.

Merle-Méjean et al. have found that on an air-calcined zirconia the hydroxyl species are H/D exchanged in contact with
$\mathrm{D}_{2}\left(507^{\circ} \mathrm{C}, 100 \mathrm{hPa}\right)$ so quickly that it gives reason to believe the $\mathrm{OH}$ species are on the surface only ${ }^{63}$. Conversely, on the steam-calcined zirconia there are some hydroxyls exchanged to deuterium-containing species so slowly (during several hours), if at all, that they must be elsewhere in the oxide, likely in the bulk ${ }^{63}$.

The presence of formate species is suggested to decrease the number of available sites for $\mathrm{H}_{2} / \mathrm{D}_{2}$ dissociation as well as partially block the path for surface transport of $\mathrm{H}$ or $\mathrm{D}$ atoms 42 . If there are formates on the surface, the H/D exchange between $\mathrm{OH}$ and $\mathrm{OD}$ species at $150{ }^{\circ} \mathrm{C}$ is $4-36$ times slower depending on the formate coverage $(0.3$ or 0.8 times the maximum coverage $)^{42}$. The overall extent of the H/D exchange of multicoordinated $\mathrm{OH}$ to $\mathrm{OD}$ is limited to $9 \%$ with formate and $2 \%$ with methoxy species as compared to normal $\mathrm{ZrO}_{2}$ surface $^{26}$.

\section{Interaction with $\mathrm{CO}$}

Upon contact with monoclinic zirconia, $\mathrm{CO}$ tends to form several surface species: at low temperatures up to $c a .100^{\circ} \mathrm{C}$ the preferred species is linearly adsorbed $\mathrm{CO}$, at higher temperatures the dominating surface species is formate. In addition to these, also carbonate and carboxylate-type species have been observed.

\subsection{Linear CO species, formation and stability}

$\mathrm{CO}$ adsorption at room temperature leads to the formation of linear CO species on cationic sites of the zirconia surface (see Fig. 8), the corresponding bands in IR spectra are located at ca. $2200-2170 \mathrm{~cm}^{-15,18,48,50}$. Spectra of the linear CO species as a function of $\mathrm{CO}$ pressure and with two differently prepared samples are shown in Fig. 9. The presence of a weak band at $2112 \mathrm{~cm}^{-1}$ is reported after $\mathrm{C}$ adsorption at room temperature $^{48}$. With adsorption below room temperature, e.g., at $-173 \ldots-195^{\circ} \mathrm{C}$, the range of adsorbed linear CO species extends to $c a$. $2200-2140 \mathrm{~cm}^{-1}$ at varying $\mathrm{CO}$ pressures (from $10^{-4}$ to 40 torr $)^{39,58}$.

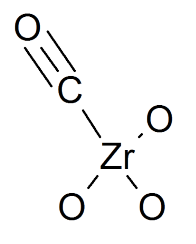

linear CO

Fig. 8 Linearly adsorbed CO species.

Morterra et al. report that the linearly adsorbed CO species seen in IR at room temperature are at wavenumbers $2198-$

This journal is @ The Royal Society of Chemistry [year]

Journal Name, 2010, [vol], 1-19 |9 

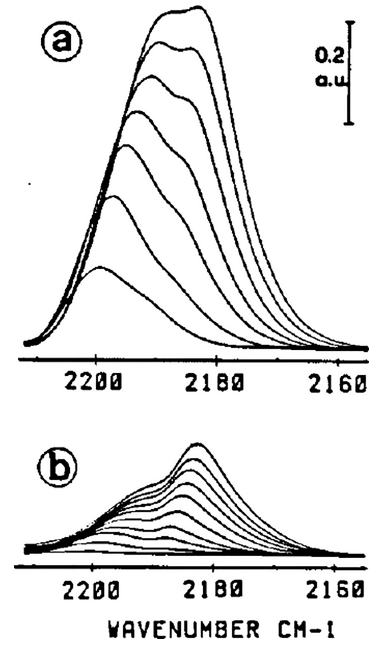

Fig. $9 \mathrm{CO}$ adsorbed at room temperature on a $\mathrm{ZrO}_{2}$ sample calcined at $597^{\circ} \mathrm{C}$ (a) and at $997^{\circ} \mathrm{C}$ (b), followed by vacuum-activation at $597^{\circ} \mathrm{C} . \mathrm{P}_{C O}=2 \cdot 10^{-1} \ldots 1.2 \cdot 10^{2}$ torr. Reproduced from ref. ${ }^{39}$ with permission. Copyright 1991, Elsevier.

$2187 \mathrm{~cm}^{-1}$ and $2188-2174 \mathrm{~cm}^{-1}$, named $(\mathrm{CO})_{H}$ and $(\mathrm{CO})_{L}$ after the high-frequency and low-frequency bands ${ }^{18}$. Also Guglielminotti has adsorbed $\mathrm{CO}$ to zirconia at room temperature, and his results for either reduced $\left(550^{\circ} \mathrm{C}\right)$ or oxidized $\left(400-550^{\circ} \mathrm{C}\right)$ and vacuum-activated $\left(400^{\circ} \mathrm{C}\right)$ samples show strong bands at around $2200 \mathrm{~cm}^{-129}$. For samples reduced at $300^{\circ} \mathrm{C}$ and/or vacuum-activated at $500^{\circ} \mathrm{C}$ after oxidation, adsorbed $\mathrm{CO}$ is observed also at $2110 \mathrm{~cm}^{-129}$.

The IR bands at $c a .2200-2190 \mathrm{~cm}^{-1}$ are interpreted as $\mathrm{CO}$ adsorbed on $\mathrm{Zr}^{4+6,27,29}$ and the band at $c a$. 2120$2110 \mathrm{~cm}^{-1}$ is assigned to $\mathrm{CO}$ on $\mathrm{Zr}^{3+}$ surface ions ${ }^{6,7,9,29,81}$, whereas ESR (electron spin resonance spectroscopy) results are interpreted so that $\mathrm{Zr}^{3+}$ surface ions do not interact with $\mathrm{CO}$ at room temperature ${ }^{47}$. The appearance of IR bands assigned to adsorbed $\mathrm{CO}$ at higher wavenumbers than gas-phase $\mathrm{CO}$ (at $2202 \mathrm{~cm}^{-1}$ ) is attributed to polarization of the $\mathrm{CO}$ molecule on the surface ${ }^{48}$. At room temperature the $\mathrm{OH}$ groups are not modified during $\mathrm{CO}$ adsorption ${ }^{54}$.

The $(\mathrm{CO})_{H}$ and $(\mathrm{CO})_{L}$ species are suggested to be on two types of Lewis-acidic centers ${ }^{18}$, both types assigned as $\mathrm{Zr}^{4+}$ ions ${ }^{27}$. For $\mathrm{CO}$ chemisorption, these centers are suggested to be caused by differences in crystallography and/or coordinative configurations as the $(\mathrm{CO})_{L}$ intensity increases while the $(\mathrm{CO})_{H}$ intensity declines with increasing activation temperature as a result of the beginning sintering process ${ }^{18}$. The $(\mathrm{CO})_{L}$ sites are therefore assigned to flat sites whereas the $(\mathrm{CO})_{H}$ sites are thought to be on rougher (high-index) planes or structural defects: steps, kinks, or corners ${ }^{27}$. Sintering the surface indeed causes a sharp relative decline on $(\mathrm{CO})_{H}$ intensity (at $c a .2190 \mathrm{~cm}^{-1}$ ) in IR, and the sintered surface seems to have more extended and regular flat surface sites based on HRTEM images ${ }^{39}$.

Linear CO is reversibly adsorbed on the surface at room temperature as removing the $\mathrm{CO}$ from gas phase results in the disappearance of its IR band ${ }^{20,27,54,55}$. CO adsorption at room temperature at constant $\mathrm{CO}$ pressure shows constant intensity against time on stream if measured by the band at $c a$. $2192 \mathrm{~cm}^{-120,54}$, indicating unactivated adsorption. Jung and Bell present an interesting scheme (see Fig. 10) relating linearly adsorbed $\mathrm{CO}$ and its interactions with the zirconia surface $^{25}$. In the scheme they show two differently coordinated adsorbed $\mathrm{CO}$ molecules with bicarbonate and bidentate carbonate as transformation intermediates: in the former case the $\mathrm{Zr}^{4+}$ cation will have a lower Lewis acidity in the vicinity of an $\mathrm{OH}$ group, leading to a lower displacement value of the IR wavenumber compared to the gas-phase CO IR band than with the bidentate carbonate intermediate in a c.u.s. oxygen environment ${ }^{25}$.
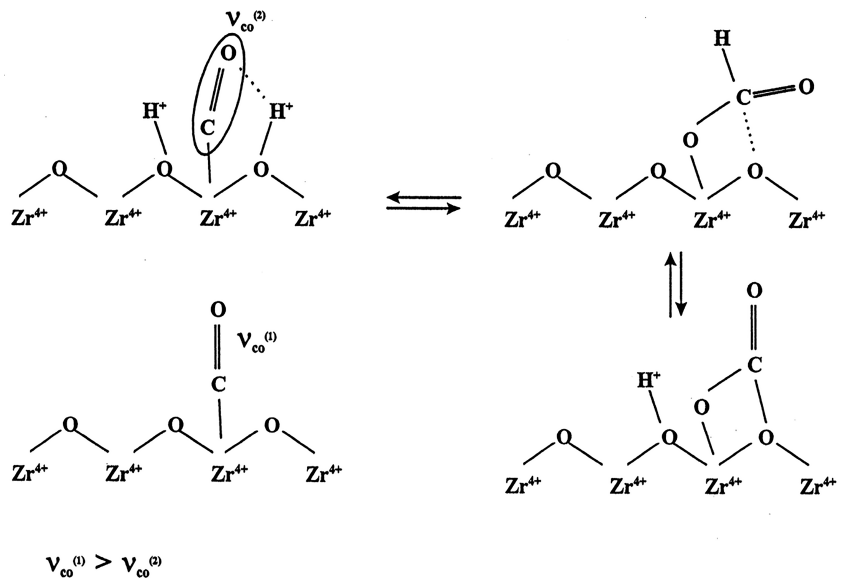

Fig. 10 Interactions of linearly adsorbed $\mathrm{CO}$ with the $\mathrm{ZrO}_{2}$ surface. Reproduced from ref. ${ }^{25}$ with permission. Copyright 2000 , Elsevier.

Increasing the $\mathrm{CO}$ partial pressure increases the adsorbed $\mathrm{CO}$ band intensity ${ }^{20,52}$. The intensity ratio for the two adsorbed $\mathrm{CO}$ species favors $(\mathrm{CO})_{H}$ at low coverages and $(\mathrm{CO})_{L}$ at high $\mathrm{CO}$ pressures ${ }^{18,27}$. An increase in the CO partial pressure shifts the IR band position down from $c a .2195 \mathrm{~cm}^{-1}$ to $2188 \mathrm{~cm}^{-127,50,52,54}$, and the overall surface area of the band indicates adsorption according to Langmuir's adsorption model with increasing CO partial pressure ${ }^{54}$.

Increasing the adsorption temperature shifts the main band at $c a .2190 \mathrm{~cm}^{-1}$ towards higher wavenumbers ${ }^{18,55}$. This shift is attributed to inductive effects, as the charge-release mechanism of the adsorbed $\mathrm{CO}$ is affected by those, as well as the influence of other surface species (e.g. $\mathrm{OH})$ on the adsorbed $\mathrm{CO}^{18}$. The temperature range with detectable linear $\mathrm{CO}$ bands extends typically to $c a$. $100-150^{\circ} \mathrm{C}^{48,54,55}$, but it has been reported even at $250^{\circ} \mathrm{C}^{25}$ at $2184.9 \mathrm{~cm}^{-1}$ (CO pressure not 
reported). Ma et al. observed a band at $2109 \mathrm{~cm}^{-1}$ during $\mathrm{CO}$ adsorption at $350^{\circ} \mathrm{C}$, linked to $\mathrm{CO}$ adsorption on c.u.s. $\mathrm{Zr}^{3+7}$.

The reported linear CO coverages are scaled to $\mu \mathrm{mol} / \mathrm{m}^{2}$ and collected in Table 5. The amount of adsorbed CO depends on the adsorption temperature, the coverage at $-173^{\circ} \mathrm{C}$ is significantly higher than the coverage at room temperature. As can be seen in Table 5, dehydroxylation increases the linear $\mathrm{CO}$ adsorption capacity ${ }^{20}$, as dehydroxylated surfaces have a higher number of bare zirconium cations. Increasing activation temperature results in increasing monolayer capacities for both $(\mathrm{CO})_{L}$ and $(\mathrm{CO})_{H}^{27}$, as expected due to lower hydroxyl coverage with increasing activation temperature. It has been estimated that $50 \%$ of the dehydroxylated sites can adsorb $\mathrm{CO}$ reversibly ${ }^{20}$. The capacity for the $(\mathrm{CO})_{H}$ species is significantly lower than for the $(\mathrm{CO})_{L}$ species, the latter almost fourfold compared to the former ${ }^{27}$.

Dulaurent and Bianchi have assumed Langmuir adsorption, calculated adsorption coefficients from IR data and used them with statistical thermodynamics to extract heats of adsorption, and their results range from $55 \mathrm{~kJ} / \mathrm{mol}$ to $42 \mathrm{~kJ} / \mathrm{mol}$ (at zero and saturation coverage, respectively) ${ }^{55}$. Molar heat of adsorption determined with microcalorimetry is reported to be $65-73 \pm 2 \mathrm{~kJ} / \mathrm{mol}$ for $(\mathrm{CO})_{H}$ and $44-50 \pm 2 \mathrm{~kJ} / \mathrm{mol}$ for $(\mathrm{CO})_{L}{ }^{27}$, and for Lewis-acidic sites at vanishing coverages $c a$. $60 \mathrm{~kJ} / \mathrm{mol}$. Based on theory, the adsorption energy of linearly adsorbed CO was determined to be $-45 \mathrm{~kJ} / \mathrm{mol}^{28}$. To give an idea of the strength of the $\mathrm{CO}$ adsorption on the $\mathrm{Zr}^{3+}$ sites, $\mathrm{CO}$ on $\mathrm{Zr}^{4+}$ (at $c a .2200 \mathrm{~cm}^{-1}$ ) can be removed by evacuation at room temperature and $\mathrm{CO}$ on $\mathrm{Zr}^{3+}$ (at $c a .2110 \mathrm{~cm}^{-1}$ ) is slightly more strongly bound to the zirconia surface, yet also possible to evacuate at room temperature ${ }^{29}$. The observed IR band intensities of the $(\mathrm{CO})_{H}$ and $(\mathrm{CO})_{L}$ species with increasing $\mathrm{CO}$ pressures are in line with their heats of adsorption: the $(\mathrm{CO})_{H}$ with a higher heat of adsorption has a higher intensity at low pressures and and vice versa at higher pressures ${ }^{27}$.

As shown in Table 5, the linear CO adsorption capacity on dehydroxylated surfaces is higher than on hydroxylated surfaces. The hydroxyl species has an adverse effect on $\mathrm{CO}$ adsorption as linear $\mathrm{CO}^{20,27,28}$, completely suppressing $\mathrm{CO}$ adsorption at room temperature already at a surface concentration of $2.4 \mu \mathrm{mol} / \mathrm{m}^{2} \mathrm{H}_{2} \mathrm{O}^{27}$, corresponding to a $20 \%$ surface coverage. The more strongly adsorbed linear $\mathrm{CO}$ species, $(\mathrm{CO})_{H}$, seems to be suppressed more than the more weakly adsorbed species when the sample is changed from a dehydroxylated one to one with a low $\mathrm{OH}$ coverage ${ }^{27}$, suggesting that the site for $(\mathrm{CO})_{H}$ is the preferred site for hydroxyl formation. Four irreversibly held water molecules are required to eliminate one acidic site based on adsorption capacity experiments at varying degrees of hydration ${ }^{27}$. This $4: 1$ ratio between water and $\mathrm{CO}$ suggests that adsorption sites for linearly adsorbed $\mathrm{CO}$ represent only a minority of the sites available for water adsorption. This division is also reflected in the ad- sorbed amounts of water or $\mathrm{OH}$ groups (Table 3) and linearly adsorbed CO (Table 5).

In addition to increasing the adsorption capacities, dehydroxylation seems to shift the bands of the adsorbed $\mathrm{CO}$ species up in wavenumber, once full dehydroxylation has been carried out by evacuation at $597^{\circ} \mathrm{C}$, the bands only decrease in intensity: especially the $(\mathrm{CO})_{H}$ band intensity decreases as is expected due to the sintering process first affecting the minority $\operatorname{sites}^{27}$. Morterra et al. indicate that on a highly hydrated surface, local interactions among hydroxyls exceed the adsorbate-adsorbate interactions caused by $\mathrm{CO}$, i.e., the ordered $\mathrm{CO}$ oscillator network is interfered with the hydroxyls present $^{39}$.

Morterra et al. have looked at $\mathrm{CO}$ adsorption to cationic $\mathrm{Zr}$ sites after rehydration and they report that the $\mathrm{CO}$ species adsorbing at $2145 \mathrm{~cm}^{-1}$ (assigned to $\mathrm{CO}$ adsorbed to $\mathrm{Zr}^{4+}$ centers via a $\sigma$ bond) are quickly suppressed with water, but the lower wavenumber band tends to downshift from $2112 \mathrm{~cm}^{-1}$ to $2102 \mathrm{~cm}^{-1}$ (proposed to be c.u.s. cationic center $\mathrm{Zr}^{n+}$, where $n<4)$ and increase in intensity ${ }^{8}$. The overall surface coverage of charge-releasing $\mathrm{CO}$ species inductively affect also the position of the adsorbed $\mathrm{CO}$ band $^{8}$.

Even though hydroxylation decreases the linear $\mathrm{CO}$ adsorption capacity 27,58 , surface hydroxyls are an important surface site for $\mathrm{CO}$ adsorption as formate species ${ }^{5,21}$. Linearly adsorbed $\mathrm{CO}$ intensities during room-temperature adsorption have been compared before and after CO adsorption at elevated temperature ${ }^{54,55}$. Dulaurent and Bianchi report that after $\mathrm{CO}$ adsorption at $85^{\circ} \mathrm{C}$ or $152^{\circ} \mathrm{C}$, cooling to $27^{\circ} \mathrm{C}$ and another $\mathrm{CO}$ adsorption, the absorbance of the linear CO band is reported to decrease by $12 \%$ or $35 \%$, respectively $^{55}$. Mugniery et al. show spectra where formate preadsorption at $300^{\circ} \mathrm{C}$ shifts the linear CO bands from $2192 \mathrm{~cm}^{-1}$ to $2177 \mathrm{~cm}^{-154}$. When these bands are compared to the spectra of Morterra et al. ${ }^{38}$ we note that the $(\mathrm{CO})_{H}$ species is suppressed by formates, linking the formate and the $(\mathrm{CO})_{H}$ to the same $\mathrm{Zr}^{4+}$ surface site. As mentioned earlier, when investigating the $\mathrm{CO}$ pressure effect on the band, $(\mathrm{CO})_{L}$ is the preferred species at high coverages. However, it is not clear whether that applies also to the increasing formate coverage (or coverage of any species) or if the $(\mathrm{CO})_{H}$ site is occupied or otherwise hindered due to the adsorbed formate species.

\subsection{Formates, formation and decomposition}

Formate species consists of a $\mathrm{HCOO}^{-}$unit connected to a surface zirconium cation from oxygen atom(s). Two different surface configurations have been proposed for the formate species: a bidentate formate $20,22,30,42$ and a monodentate formate 22,42 shown in Fig. 11. Main IR bands of formate species on monoclinic zirconia are observed typically (see Fig. 12) at ca. $2965 \mathrm{~cm}^{-1}, 2880 \mathrm{~cm}^{-1}, 1565 \mathrm{~cm}^{-1}, 1387 \mathrm{~cm}^{-1}$, 
Table 5 Linear CO coverages reported in literature

\begin{tabular}{|c|c|c|c|c|c|}
\hline Measurement & As reported & Scaled to $\mu \mathrm{mol} / \mathrm{m}^{2}$ & $T_{a d s}$ & $P_{C O}$ & Ref. \\
\hline Adsorbed quantities of $\mathrm{CO}^{\mathrm{a}}$ & up to $220 \mu \mathrm{mol} / \mathrm{g}$ & up to 2.7 & RT & N/A & 50 \\
\hline Monolayer $(\mathrm{ML})$ capacity for $(\mathrm{CO})_{H}$ & $0.12-0.24$ molec. $/ \mathrm{nm}^{2}$ & $0.2-0.4$ & RT & 70 or 20 torr $^{b}$ & 27 \\
\hline Monolayer (ML) capacity for $(\mathrm{CO})_{L}$ & $0.5-0.8$ molec. $/ \mathrm{nm}^{2}$ & $0.8-1.3$ & $\mathrm{RT}$ & N/A ${ }^{c}$ & 27 \\
\hline Monolayer coverage for $\mathrm{CO}$ & $0.65 \mathrm{CO}$ sites $/ \mathrm{nm}^{2}$ & 1.1 & RT & 60 torr & 52 \\
\hline ML capacity for fully dehydroxylated sample & 1.04 molec. $/ \mathrm{nm}^{2}$ & 1.73 & RT & N/A & 27 \\
\hline $\mathrm{Zr}^{+\delta}$ sites available for linear $\mathrm{CO}$ adsorption & $8 \cdot 10^{13} \mathrm{sites} / \mathrm{cm}^{2}$ & 1.33 & RT & N/A & 55 \\
\hline Total CO coverage on a hydroxylated surface & 2.7 molec. $/ \mathrm{nm}^{2}$ & 4.5 & $-173^{\circ} \mathrm{C}$ & $260 \mathrm{~Pa}$ & 58 \\
\hline Total CO coverage on a dehydroxylated surface & 3.8 molec. $/ \mathrm{nm}^{2}$ & 6.3 & $-173^{\circ} \mathrm{C}$ & $260 \mathrm{~Pa}$ & 58 \\
\hline
\end{tabular}

a Assuming full adsorption on the surface from fed known amount of CO. IR band in the presence of CO gas at 800 Pa is thrice as intensive as the one with $2.7 \mu \mathrm{mol} / \mathrm{m}^{2}$.

${ }^{\text {b }}$ Saturation pressure, 70 torr for samples activated at $397^{\circ} \mathrm{C}$ and $597^{\circ} \mathrm{C}, 20$ torr for sample activated at $797^{\circ} \mathrm{C}$.

${ }^{c}$ Estimated to be $30 \%$ higher than adsorption capacity at 130 torr.

$1379 \mathrm{~cm}^{-1}$ and $c a . \quad 1365 \mathrm{~cm}^{-15,19,22,23,88}$, listed with their originating vibrations as well as thoretical IR bands in Table 6 . Unlike for the linearly adsorbed $\mathrm{CO}$ species, formate formation (see Eq. 2) is an activated process, and its rate expression is shown in Eq. 3.<smiles>O=[C]O[Z](O)O</smiles>

monodentate formate<smiles></smiles>

chelating bidentate formate<smiles>O[Z]1OC=[Z](O)O1</smiles>
bridging bidentate formate
Fig. 11 Monodentate and bidentate formate species.

$$
\begin{gathered}
\mathrm{CO}+\mathrm{OH} * \leftrightarrow \mathrm{COOH} * \\
r_{f}=k \cdot P_{\mathrm{CO}} \cdot[\mathrm{OH} *]
\end{gathered}
$$

Due to the activated formation process, at low temperatures $\left(\right.$ e.g. $\left.T<200^{\circ} \mathrm{C}\right)$ the adsorption time affects the amount of formate formed, whereas at high temperatures the system quickly reaches equilibrium, however, the equilibrium coverage is also temperature-dependent. The activated nature of the process is demonstrated with increasing intensity of the formate IR bands at different temperatures $\left(25-350^{\circ} \mathrm{C}\right)$ with adsorption times ranging from $30 \mathrm{~min}$ up to $18 \mathrm{~h}^{19,42,54}$. Formate formation requires rearrangement of at least three bonds, the cleavage of the $\mathrm{O}-\mathrm{H}$ bond, and the formation of the $\mathrm{O}-\mathrm{C}$ and the $\mathrm{C}-\mathrm{H}$ bonds ${ }^{28}$. The theory-based estimate for the activation energy of formate formation is $154 \mathrm{~kJ} / \mathrm{mol}^{28}$, which
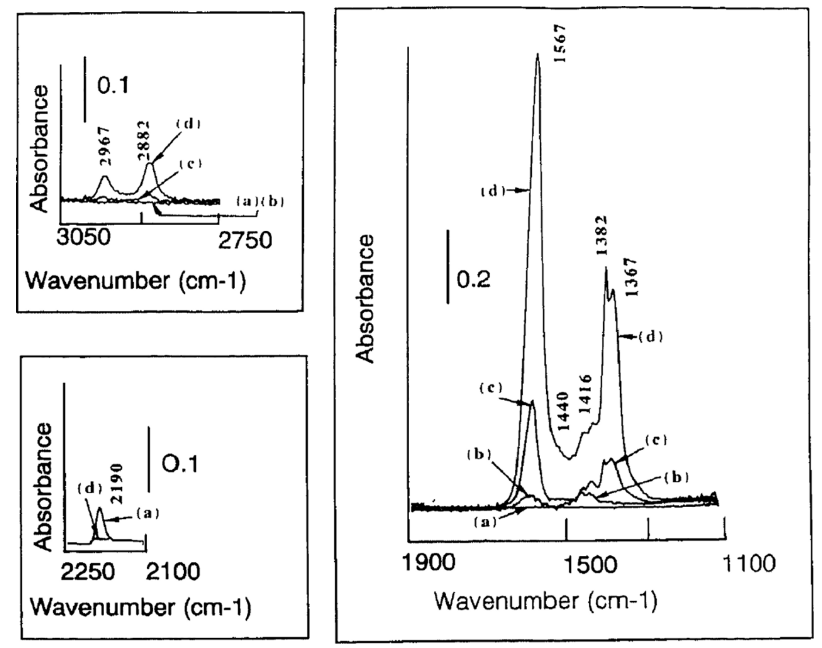

Fig. 12 Formate and linear $\mathrm{CO}$ spectra at (a) $25^{\circ} \mathrm{C}$, (b) $150^{\circ} \mathrm{C}$, (c) $250^{\circ} \mathrm{C}$, and (d) $350^{\circ} \mathrm{C}$ in $5 \% \mathrm{CO} / \mathrm{He}$. Reprinted from ref. ${ }^{20}$ with permission. Copyright 1993, Elsevier.

is in agreement with the experimental observations, yet no experimental value for the activation energy has been reported.

Overall the temperature range of formate observations is wide, ranging from $c a .85^{\circ} \mathrm{C}$ up to $550^{\circ} \mathrm{C}^{7,20,24,25,28,48,55}$. The formate intensity maximum is at $c a .300-400^{\circ} \mathrm{C}^{23,28}$, depending on the pretreatment and measurement conditions, with increasing intensities reported at lower temperatures ${ }^{48}$. All in all, the formate coverage depends on the adsorption conditions (temperature, $\mathrm{CO}$ pressure) and the contact time with $\mathrm{CO}$. With increasing temperature $\left(240-400^{\circ} \mathrm{C}\right)$ the formate coverage decreases ${ }^{23}$ while formate intensity increases with increasing $\mathrm{CO}$ concentration in the gas phase ${ }^{23}$. Silver et al. have adsorbed $\mathrm{CO}$ on pure $\mathrm{ZrO}_{2}$ at $500^{\circ} \mathrm{C}$ and they only discovered formates on the surface, no (bi)carbonates or adsorbed CO species ${ }^{45}$. 
Table 6 Experimentally and theoretically ${ }^{\mathrm{a}}$ determined formate wavenumbers

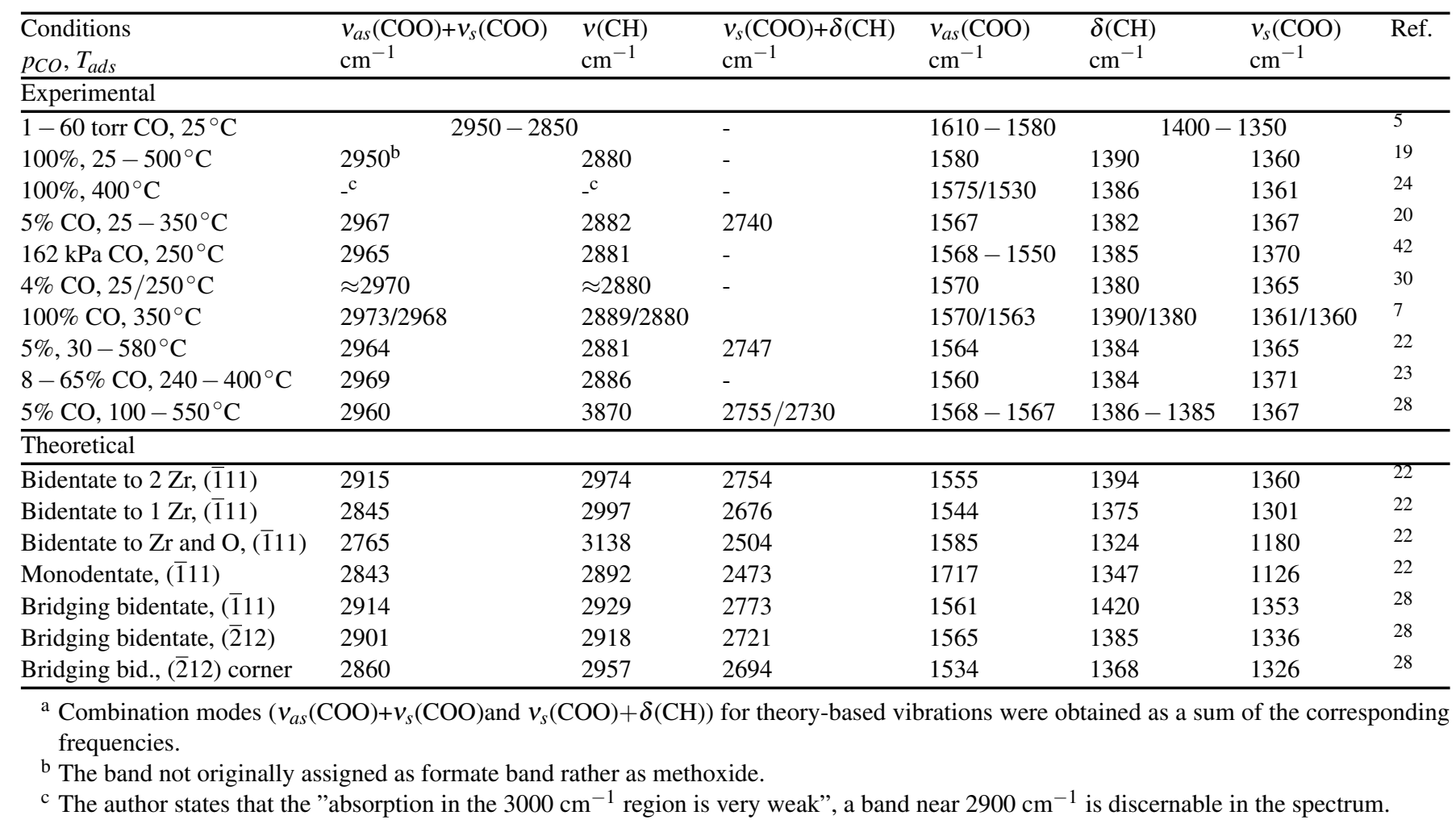

At $250^{\circ} \mathrm{C}$ the monodentate formate has a maximum at $1589 \mathrm{~cm}^{-1}$ and bidentate formate has maxima at $1568 \mathrm{~cm}^{-1}$, $1388 \mathrm{~cm}^{-1}$ and $1371 \mathrm{~cm}^{-142}$. The authors also suggest that the formation of monodentate formate is intensified with increasing time in contact with $\mathrm{CO}$, in agreement with activated formation process, and that the shift from bidentate to monodentate formates is due to repulsion among the bidentate formates at high surface concentrations ${ }^{42}$ as shown with increasing time-on-stream $\left(\mathrm{CO}\right.$ at $\left.250^{\circ} \mathrm{C}\right)$ at $1568 \mathrm{~cm}^{-1}$ separating into two bands at $1589 \mathrm{~cm}^{-1}$ and $1556 \mathrm{~cm}^{-1}$.

According to Bianchi et al., the formate species would be probably a bidentate as the difference between the observed bands at $1567 \mathrm{~cm}^{-1}\left(\mathrm{v}_{a s}(\mathrm{OCO})\right)$ and $1367 \mathrm{~cm}^{-1}\left(\mathrm{v}_{s}(\mathrm{OCO})\right)$ is $200 \mathrm{~cm}^{-120}$, and the same deduction has been used by Ma et al. for formate bands at $1570 \mathrm{~cm}^{-1}$ and $1361 \mathrm{~cm}^{-17}$, both assigning the species based on the band separation. For carbonates, the typical difference should be $c a .100 \mathrm{~cm}^{-1}$ in the monodentate case and $300 \mathrm{~cm}^{-1}$ in the bidentate case ${ }^{89}$. Bianchi et al. also state that another formate species might cause the band at $1382 \mathrm{~cm}^{-1}$; however, it should also have a doublet band near $1570 \mathrm{~cm}^{-1}$, close to the one of the bidentate formate $^{20}$.

Korhonen et al. have suggested a reaction scheme where the bidentate formate formation proceeds via an activated mono- dentate complex ${ }^{22}$. They state that based on DFT calculations the formate is likely in a bidentate configuration as the monodentate is unlikely to be stable ${ }^{22}$. Our investigations indicate a bridging bidentate formate configuration as the most stable geometry on all the tested surfaces ${ }^{28}$.

Formate forms on a surface hydroxyl species. Pozdnyakov and Filimonov stated already in 1972 that the formate is formed due to $\mathrm{CO}$ reacting with the surface hydroxyls ${ }^{5}$. Yamaguchi et al. in 1978 have shown formation of formate and disappearance of terminal $\mathrm{OH}$ and multicoordinated $\mathrm{OH}$ bands following the adsorption of deuterated acetone- $d_{6}$, the terminal $\mathrm{OH}$ being more reactive toward formates than the multicoordinated one ${ }^{59}$. Amount of formate formed is dependent on the surface hydroxyls, a decrease in formate formation shown by Jackson and Ekerdt by removing water from $\mathrm{CO} / \mathrm{H}_{2}$ feed ${ }^{10}$ and by Bianchi et al. by dehydroxylating the surface ${ }^{20}$. He and Ekerdt suggested that formate formation proceeds via gasphase $\mathrm{CO}$ and surface $\mathrm{OH}$ group ${ }^{21}$.

Formate formation has been reported at low temperatures $\left(25^{\circ} \mathrm{C} \text { and } 160^{\circ} \mathrm{C} \text { ) on terminal OH (IR band at } 3770 \mathrm{~cm}^{-1}\right)^{20}$. In addition to the terminal $\mathrm{OH}$ site, formate formation on multicoordinated $\mathrm{OH}$ (band at $3680 \mathrm{~cm}^{-1}$ ) has been reported at higher temperatures $\left(250-350^{\circ} \mathrm{C}\right)^{7,20,42}$; however, some experimental $^{23}$ and theoretical ${ }^{22}$ results do not support the par- 
ticipation of the multicoordinated $\mathrm{OH}$ species. Jung and Bell suggested that the primary route for formate formation is via gas-phase $\mathrm{CO}$ and an $\mathrm{OH}$ group, after 9 hours at $250^{\circ} \mathrm{C}$ and $162 \mathrm{kPa} \mathrm{CO}$, all terminal hydroxyl species are consumed to formate formation as well as $38 \%$ of the bridged hydroxyl species $^{42}$. Based on their spectral evidence ${ }^{42}$, it seems that the consumption of terminal $\mathrm{OH}$ species is faster than that of multicoordinated $\mathrm{OH}$ species, yet whether all bridged hydroxyls can be consumed is unclear based on the evidence.

Jackson and Ekerdt suggested that formate formation in methanol synthesis involves an oxygen vacancy and an adjacent bridged hydroxyl site so that there is a terminal $\mathrm{CO}$ intermediate, the scheme is shown in Fig. $13^{10}$. However, their suggestion is in contradiction with some more recent results reporting that indeed the terminal hydroxyls participate in the formate formation ${ }^{23,42}$.<smiles>[Z7]O[Z]1O[Z](O[Z17])O1</smiles>

Fig. 13 Proposed formate formation mechanism as a part of methanol synthesis over $\mathrm{ZrO}_{2}$. Adapted from ref. ${ }^{10}$ with permission. Copyright 1986, Elsevier.

Formate decomposition has been proposed to take place by two different pathways: dehydrogenation producing $\mathrm{CO}_{2}$ and $\mathrm{H}_{2}$, and dehydration releasing $\mathrm{CO}$ and $\mathrm{H}_{2} \mathrm{O}$, to follow the naming of $\mathrm{He}$ and Ekerdt ${ }^{21}$. Similar decomposition pathways have been proposed by Bianchi et al. suggesting the release of $\mathrm{CO}$ and restoring the $\mathrm{OH}$ groups ${ }^{20}$, and in our investigations suggesting that the dehydration is two separate reactions: first reversible formate decomposition to $\mathrm{CO}$ resuming surface hydroxyls and then dehydroxylation to produce $\mathrm{H}_{2} \mathrm{O}$, as the dehydroxylation process is observed at a similar temperature range also without $\mathrm{CO}$ present in the gas phase ${ }^{28}$. A lower limit estimate for the activation energy for the dehydrogenation reaction is its reaction energy at $178-363 \mathrm{~kJ} / \mathrm{mol}$ based on theory ${ }^{28}$. The typical temperature range for formate de- composition is above $300^{\circ} \mathrm{C}^{28}$, a desorption maximum has been reported at $410^{\circ} \mathrm{C}^{20}$. The activated formate formation (increasing uptake rate up to $300^{\circ} \mathrm{C}$ ) and the formate decomposition pathways are demonstrated in Figure 14, where the zirconia sample is linearly heated from $100^{\circ} \mathrm{C}$ to $550{ }^{\circ} \mathrm{C}$ in the presence of $2 \% \mathrm{CO}$, the $\mathrm{y}$-axis corresponds to release/uptake from the sample.

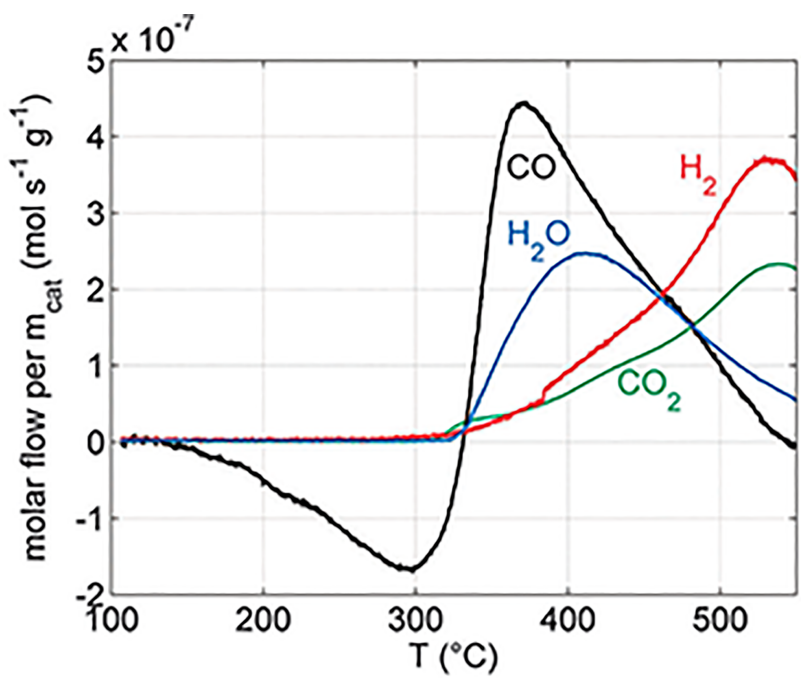

Fig. 14 Temperature-programmed surface reaction (TPSR) in the presence of $\mathrm{CO}$ on reduced $\mathrm{ZrO}_{2}$. The y-axis corresponds to release $(+)$ or uptake (-) from the sample. Reproduced from ref. ${ }^{28}$ with permission from the PCCP Owner Societies.

Bianchi et al. have reported amounts of $\mathrm{CO}, \mathrm{CO}_{2}$ and $\mathrm{H}_{2}$ that have adsorbed/desorbed during temperature-programmed desorption (TPD) after CO adsorption ${ }^{20}$. Not all carbon species are recovered, suggesting that the surface is not empty of formate ( $c$ a. $10 \%$ of the $\mathrm{CO}$ adsorbed at $350^{\circ} \mathrm{C}$ unaccounted for) by the end of the desorption process with $T_{\max }$ at $410^{\circ} \mathrm{C}^{20}$. Based on the observed $\mathrm{CO}_{2} / \mathrm{H}$ ratio the surface species is claimed to be formate ${ }^{20}$. The decomposition routes of formate have been reported to be either completely reversible decomposition resulting in restoring the terminal hydroxyls ${ }^{23}$ or that only about $20 \ldots 40 \%$ of formate decompose forming hydrogen while the rest is decomposed reversibly ${ }^{20,28}$. For ceria-based catalysts, the presence of coadsorbed water on the catalyst significantly increased the decomposition rate of formate to $\mathrm{CO}_{2}$ and $\mathrm{H}_{2}{ }^{90,91}$ and the same likely applies to zirconia as well. Also Korhonen et al. report observations of $\mathrm{CO}_{2}$ as formate decomposition product above $500^{\circ} \mathrm{C}^{22}$. The presence of an active metal (e.g. platinum) increases the rate of formate decomposition to $\mathrm{CO}_{2}$ and $\mathrm{H}_{2}{ }^{23}$, presumably by associating hydrogen (analogous to water-gas shift reaction), enabling a reasonable temperature window instead of $500^{\circ} \mathrm{C}$ or more.

The adsorption temperature has a significant effect on the 
amount of $\mathrm{CO}$ desorbed from the surface as $\mathrm{CO}_{2}$ during TPD, yet the overall profile of the $\mathrm{CO}_{2}$ desorption curve remains qualitatively similar ${ }^{30}$. CO desorption was clearly observable only after adsorption at $200^{\circ} \mathrm{C}$ or $250^{\circ} \mathrm{C}$. At $250^{\circ} \mathrm{C}$ there are formates on the surface according to $\mathrm{IR}^{30}$, thus the $\mathrm{CO}$ desorption is likely due to decomposition of surface formate species and the $\mathrm{CO}_{2}$ originates from formates or, especially after low-temperature adsorption of $\mathrm{CO}$, (bi)carbonate species. The temperature of maximum desorption was in the range of $330^{\circ} \mathrm{C}$ for $\mathrm{CO}_{2}$ and $330-430^{\circ} \mathrm{C}$ for $\mathrm{CO}$ desorbing after $\mathrm{CO}$ adsorption.

Köck et al. have adsorbed $\mathrm{CO}$ on $\mathrm{ZrO}_{2}$ from room temperature up until $600^{\circ} \mathrm{C}$, yet their pretreatment (annealing at $900^{\circ} \mathrm{C}$ and thereafter oxidation at $600^{\circ} \mathrm{C}$ ) of the sample has quenched most of the surface hydroxyls, leaving formate formation negligible and thus supporting the formate formation mechanism based on surface hydroxyl species ${ }^{62}$.

If $\mathrm{CO}$ adsorption at $85-250^{\circ} \mathrm{C}$ is followed by cooling down to $25^{\circ} \mathrm{C}$, the intensity of the linear $\mathrm{CO}$ band at $2190 \mathrm{~cm}^{-1}$ is smaller (by $12 \%$ with $T_{a d s}$ at $85^{\circ} \mathrm{C}, 35 \%$ at $152^{\circ} \mathrm{C}$ ) with increasing preadsorption temperature compared to room temperature preadsorption ${ }^{20,55}$. This is assigned to the formation of formate species at cationic $\mathrm{Zr}$ sites ${ }^{54}$ which are thought to be the sites where CO adsorbs linearly ${ }^{6,18,27,29}$. When combined with our observations that formate formation at $100^{\circ} \mathrm{C}$ in the presence of $\mathrm{CO}$ in the gas phase is accompanied by decreasing linear $\mathrm{CO}$ intensity (see Figure 15$)^{28}$, it is suggested that site competition takes place and that linear $\mathrm{CO}$ facilitates formate formation compared to gas-phase $\mathrm{CO}$. Assuming a bidentate formate species formed on a terminal $\mathrm{OH}$ and bound to a $\mathrm{Zr}$ cation (see Fig. 11), the cation site necessary for linear $\mathrm{CO}$ adsorption is blocked by the formate.

Measured adsorbed or desorbed $\mathrm{CO}$ amounts reported in literature are collected in Table 7. Increasing adsorbed/desorbed amounts of $\mathrm{CO}$ are reported with increasing adsorption temperature up to $350^{\circ} \mathrm{C}^{20,30}$. Both Bianchi et al. ${ }^{20}$ and Pokrovski et al. ${ }^{30}$ have applied a similar TPD method, where adsorption is carried out at elevated temperature ( $T_{a d s}$ in the table) followed by cooling to room temperature, and thereafter temperature-programmed heating begins. The desorbed amount of $\mathrm{CO}_{x}$ reported by Bianchi et al. ${ }^{20}\left(0.12 \mu \mathrm{mol} / \mathrm{m}^{2}\right)$ are significantly lower than those reported by Pokrovski et al. ${ }^{30}\left(0.35 / 1.34 \mu \mathrm{mol} / \mathrm{m}^{2}\right)$ after adsorption at $250^{\circ} \mathrm{C}$, while the specific surface areas are $c a .200 \mathrm{~m}^{2} / \mathrm{g}$ and $19 / 110 \mathrm{~m}^{2} / \mathrm{g}$, respectively. The values reported in our recent work ${ }^{28}$ seem to be larger than those by others; this might be explained with a different experimental procedure, where weakly bound $\mathrm{CO}$ is not removed from the surface prior to temperatureprogramming.

As mentioned previously, the terminal $\mathrm{OH}$ group is the active species concerning formate or bicarbonate formation on the zirconia surface after gas-phase adsorption of $\mathrm{CO}$ at ele- vated temperature $\left(240-400^{\circ} \mathrm{C}\right)^{23}$. The activity of the terminal $\mathrm{OH}$ group has been further investigated using isotopelabeled experiments with $\mathrm{D}_{2} \mathrm{O}$ and $\mathrm{D}_{2}$. When deuterated formates were formed via $\mathrm{CO}$ adsorption to OD (deuteroxyl) species, they could be transformed back to $\mathrm{HCOO}$ with contact to hydrogen at $200^{\circ} \mathrm{C}^{19}$. H/D isotope exchange of the surface formates with gas-phase $\mathrm{D}_{2}$ seems to be possible, yet slow and competing with formate decomposition already around $300^{\circ} \mathrm{C}^{26}$. Only $2-3 \%$ of the surface formate species are exchanged to DCOO species at $150{ }^{\circ} \mathrm{C}$ in $488 \mathrm{kPa} \mathrm{D}_{2}{ }^{42}$. The necessity of gas-phase $\mathrm{D}_{2}$ for formate scrambling was demonstrated as the H/D exchange did not proceed between formates and surface deuteroxyls ${ }^{26}$. However, as formates can form on surface deuteroxyls achieved by surface treatment with $\mathrm{D}_{2} \mathrm{O}^{19}$, it is implied that once formed, formates are stable and do not scramble with each other via cleavage of the $\mathrm{O}_{\text {support }}-\mathrm{C}$ bond.

\subsection{Other species formed during interaction with $\mathrm{CO}$}

In addition to linear $\mathrm{CO}$ and formates also other species have been observed during $\mathrm{CO}$ adsorption. These species reveal the diversity of the interaction between $\mathrm{CO}$ and monoclinic zirconia although the number of reported observations remains low. The observed species include bidentate carbonates ${ }^{48}$, probably also carboxylate species as the band at $1416 \mathrm{~cm}^{-1}$ and its symmetric counterpart at $1560 \mathrm{~cm}^{-1}$ have been confirmed via difference spectra ${ }^{20}$. Monodentate carbonate $\left(1469 \mathrm{~cm}^{-1}\right)$ and ion carbonate bands $\left(1303 \mathrm{~cm}^{-1}\right.$ and $\left.1442 \mathrm{~cm}^{-1}\right)$ were observed after $\mathrm{CO}$ adsorption at $350^{\circ} \mathrm{C}^{7}$. Similarly, ionic carbonate and carboxylate species have been suggested, their bands disappear when $\mathrm{CO}$ is removed from the gas phase at $400^{\circ} \mathrm{C}$ while the formate species remain intact ${ }^{54}$. When comparing $\mathrm{CO}$ adsorption at $350^{\circ} \mathrm{C}$ on hydroxylated and dehydroxylated samples, the latter shows less intense formate bands but more intense bands at $1440 \mathrm{~cm}^{-1}$ and $1416 \mathrm{~cm}^{-1}$ as well as new bands at $1540 \mathrm{~cm}^{-1}$ and $1317 \mathrm{~cm}^{-1}$, suggesting carbonates present on the surface and perhaps also carboxylate species ${ }^{20}$. Also bidentate carbonates have been reported form during high-temperature adsorption (above $250^{\circ} \mathrm{C}$ ) of $\mathrm{CO}^{48}$. Ma et al. have suggested that bicarbonate and carbonate species could be formed on $\mathrm{ZrO}_{2}$ from $\mathrm{CO}$ via carboxylate surface species ${ }^{7}$. He and Ekerdt have suggested that $\mathrm{CO}$ is adsorbed on the metal oxide oxygen forming a [COO] intermediate and then reacting further to carbonate or formate ${ }^{21}$. All these species require the participation of one or two surface oxygen atoms.

$\mathrm{CO}$ adsorption followed by carbonate formation and $\mathrm{CO}_{2}$ desorption leads to surface reduction as oxygen is removed from the surface. During temperature-programmed surface reaction (TPSR) in $\mathrm{CO}, \mathrm{CO}_{2}$ amounts detected correspond to $10-14 \%$ of surface oxygen atoms depending on pretreat- 

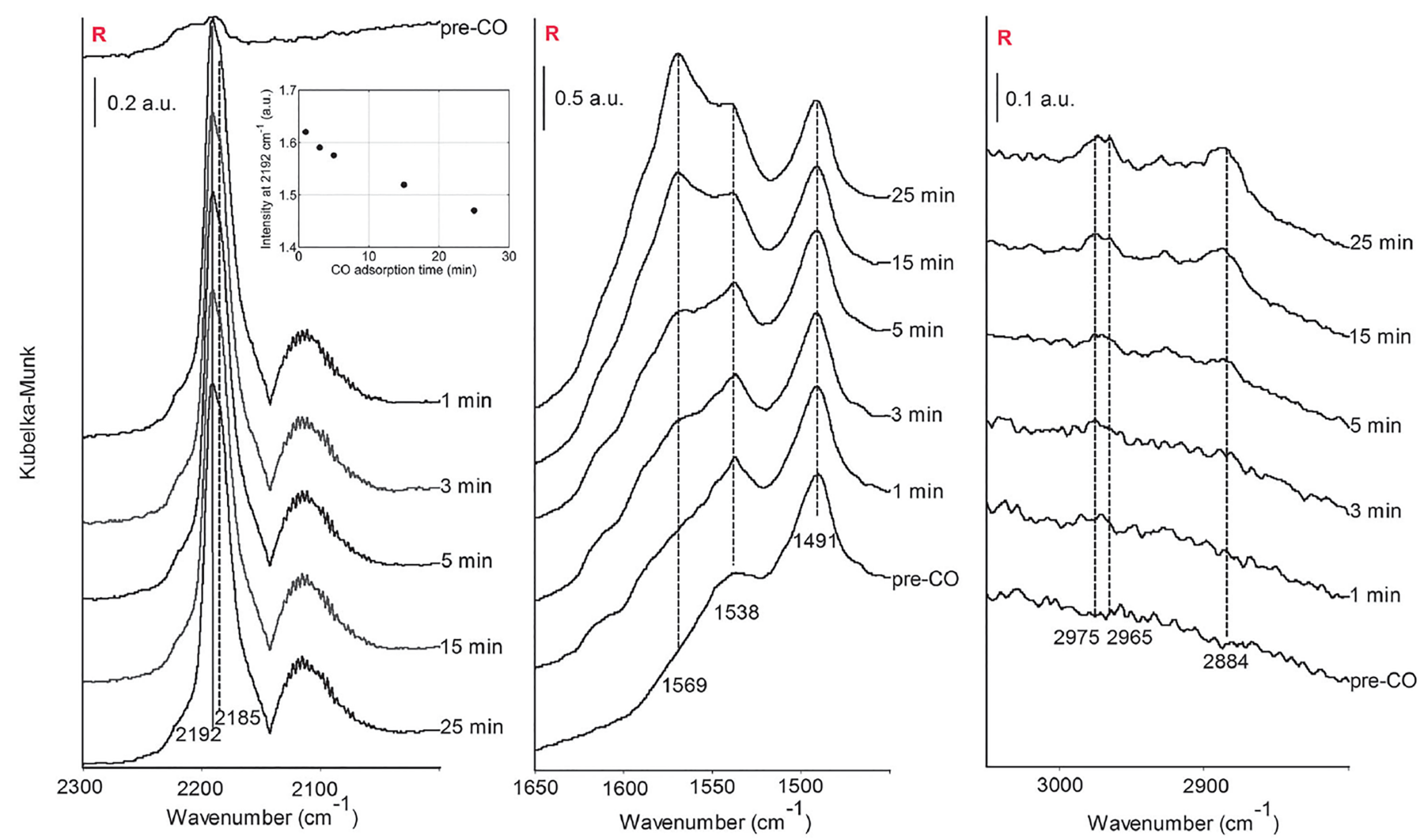

Fig. 15 Decreasing linearly adsorbed CO intensity (at $\left.2192-2185 \mathrm{~cm}^{-1}\right)$ and increasing formate intensity $\left(\right.$ at $1569 \mathrm{~cm}^{-1}, 1538 \mathrm{~cm}{ }^{-1}$, $2975-2965 \mathrm{~cm}^{-1}$ and $2884 \mathrm{~cm}^{-1}$ ) with time in contact with $\mathrm{CO}$ at $100^{\circ} \mathrm{C}$. Reproduced from ref. ${ }^{28}$ with permission from the PCCP Owner Societies.

ment of the zirconia ${ }^{28}$. Pulse oxidation experiments show that estimating the monolayer coverage based on assuming a $\mathrm{ZrO}_{2}(100)$ surface, $13.6 \%$ of the surface oxygen atoms can be removed by $\mathrm{CH}_{4}$ at $900^{\circ} \mathrm{C}^{92}$.

During static adsorption of $\mathrm{CO}$ at $200^{\circ} \mathrm{C}$ and above, $\mathrm{CO}_{2}$ formation was observed in the IR spectra, originating either from formate decomposition or from $\mathrm{CO}$ oxidation via lattice oxygen species ${ }^{62}$. Ionic carbonate was observed during $\mathrm{CO}$ adsorption at $150^{\circ} \mathrm{C}$ and above on rehydrated zirconia, and it was released as $\mathrm{CO}_{2}$ instead of $\mathrm{CO}^{20}$.

Silver et al. reported a small bicarbonate desorption peak during temperature-programmed heating in $\mathrm{CO}\left(25-620^{\circ} \mathrm{C}\right)$, however, no gas-phase $\mathrm{CO}_{2}$ or IR bands of carbonates or bicarbonates were observed during $\mathrm{CO}$ exposure at $500^{\circ} \mathrm{C}^{45}$. These observations suggest that formation of bicarbonates takes place below $500^{\circ} \mathrm{C}$, as expected based on the knowledge of bicarbonate species (for more information, see $^{28}$ and references therein).

\section{Future perspectives}

As both monoclinic zirconia and its interaction with $\mathrm{CO}$ have been investigated for more than 40 years, in some regions knowledge is still lacking. The surface configuration is one of the remaining questions, as the most stable surfaces according to density functional theory are different from those assumed based on HRTEM, yet the amount of independent experimental observations on clearly monoclinic samples remain few. The stability of the surface structure in the reaction conditions and during the reaction should be investigated carefully. Also the IR designation of terminal and multicoordinated hydroxyls (or any of the other interpretations) remains without irresputable evidence, even though the multi-oxide studies by Tsyganenko and Filimonov ${ }^{3,71}$ were very thorough in providing comparable information of several oxides with presumably different $\mathrm{OH}$ groups due to their crystal structure. Especially in the light of theoretical calculations suggesting mostly terminal and bibridged hydroxyl species, further confirmation of the assignment would provide more clarity. The $\mathrm{Zr}$ cations $\left(\mathrm{Zr}^{3+}, \mathrm{Zr}^{4+}\right)$ have also caused some confusion: the basis for the IR assignment is unclear, yet the trivalent species have 
Table 7 Adsorbed or desorbed CO amounts reported in literature

\begin{tabular}{|c|c|c|c|c|c|c|}
\hline Measurement & As reported & $\begin{array}{l}\text { Scaled to } \\
\mu \mathrm{mol} / \mathrm{m}^{2}\end{array}$ & $\begin{array}{l}T_{a d s} \\
{ }^{\circ} \mathrm{C}\end{array}$ & $P_{C O}$ & $\begin{array}{l}t_{a d s} \\
\mathrm{~min}\end{array}$ & Ref. \\
\hline Adsorbed CO (MS) & $0 \mu \mathrm{mol} / \mathrm{g}$ & 0 & 25 & $5 \%$ & N/A & 20 \\
\hline Adsorbed CO (MS) & $10 \mu \mathrm{mol} / \mathrm{g}$ & 0.050 & 150 & $5 \%$ & N/A & 20 \\
\hline Adsorbed CO (MS) & $26 \mu \mathrm{mol} / \mathrm{g}$ & 0.13 & 250 & $5 \%$ & N/A & 20 \\
\hline Adsorbed CO (MS) & $37 \mu \mathrm{mol} / \mathrm{g}$ & 0.19 & 350 & $5 \%$ & N/A & 20 \\
\hline Desorbed $\mathrm{CO}_{x}(\mathrm{MS})$ & $6.5 \mu \mathrm{mol} / \mathrm{g}$ & 0.033 & 150 & $5 \%$ & N/A & 20 \\
\hline Desorbed $\mathrm{CO}_{x}(\mathrm{MS})$ & $23 \mu \mathrm{mol} / \mathrm{g}$ & 0.12 & 250 & $5 \%$ & N/A & 20 \\
\hline Desorbed $\mathrm{CO}_{x}(\mathrm{MS})$ & $33.6 \mu \mathrm{mol} / \mathrm{g}$ & 0.17 & 350 & $5 \%$ & N/A & 20 \\
\hline Desorbed $\mathrm{CO}_{x}(\mathrm{MS})$ & $0.09 \mu \mathrm{mol} / \mathrm{m}^{2}\left(\mathrm{SA}=19 \mathrm{~m}^{2} / \mathrm{g}\right)$ & 0.09 & 25 & $4 \%$ & 20 & 30 \\
\hline Desorbed $\mathrm{CO}_{x}(\mathrm{MS})$ & $0.17 \mu \mathrm{mol} / \mathrm{m}^{2}\left(\mathrm{SA}=19 \mathrm{~m}^{2} / \mathrm{g}\right)$ & 0.17 & 150 & $4 \%$ & 20 & 30 \\
\hline Desorbed $\mathrm{CO}_{x}(\mathrm{MS})$ & $0.22 \mu \mathrm{mol} / \mathrm{m}^{2}\left(\mathrm{SA}=19 \mathrm{~m}^{2} / \mathrm{g}\right)$ & 0.22 & 200 & $4 \%$ & 20 & 30 \\
\hline Desorbed $\mathrm{CO}_{x}(\mathrm{MS})$ & $0.35 \mu \mathrm{mol} / \mathrm{m}^{2}\left(\mathrm{SA}=19 \mathrm{~m}^{2} / \mathrm{g}\right)$ & 0.35 & 250 & $4 \%$ & 20 & 30 \\
\hline Desorbed $\mathrm{CO}_{x}(\mathrm{MS})$ & $0.51 \mu \mathrm{mol} / \mathrm{m}^{2}\left(\mathrm{SA}=110 \mathrm{~m}^{2} / \mathrm{g}\right)$ & 0.51 & 25 & $4 \%$ & 20 & 30 \\
\hline Desorbed $\mathrm{CO}_{x}(\mathrm{MS})$ & $0.46 \mu \mathrm{mol} / \mathrm{m}^{2}\left(\mathrm{SA}=110 \mathrm{~m}^{2} / \mathrm{g}\right)$ & 0.46 & 150 & $4 \%$ & 20 & 30 \\
\hline Desorbed $\mathrm{CO}_{x}(\mathrm{MS})$ & $0.59 \mu \mathrm{mol} / \mathrm{m}^{2}\left(\mathrm{SA}=110 \mathrm{~m}^{2} / \mathrm{g}\right)$ & 0.59 & 200 & $4 \%$ & 20 & 30 \\
\hline Desorbed $\mathrm{CO}_{x}(\mathrm{MS})$ & $1.34 \mu \mathrm{mol} / \mathrm{m}^{2}\left(\mathrm{SA}=110 \mathrm{~m}^{2} / \mathrm{g}\right)$ & 1.34 & 250 & $4 \%$ & 20 & 30 \\
\hline Adsorbed CO (gravimetric) & $3-20 \cdot 10^{17}$ molec. $/ \mathrm{m}^{2 \mathrm{a}}$ & $0.5-3.3^{\mathrm{a}}$ & 500 & $1 \mathrm{~atm}$ & 30 & 45 \\
\hline Net desorbed $\mathrm{CO}_{x}$ at $100-550^{\circ} \mathrm{C}(\mathrm{MS})$ & $240-530 \mu \mathrm{mol} / \mathrm{g}^{\mathrm{b}}$ & $2.7-5.9^{b}$ & $100^{\mathrm{b}}$ & $2 \%$ & $90^{\mathrm{a}}$ & 28 \\
\hline
\end{tabular}

${ }^{\text {a }}$ Depending on sample preparation temperature $\left(600-900^{\circ} \mathrm{C}\right)$.

${ }^{\mathrm{b}}$ Depending on pretreatment (hydration, reduction, reduction and hydration). $\mathrm{CO}$ contact first 90 min at $100^{\circ} \mathrm{C}$, then continuing during heating up to $550^{\circ} \mathrm{C}$.

been successfully probed with $\mathrm{N}_{2} \mathrm{O}^{6}$. The EPR assignment of $\mathrm{Zr}^{3+}$ species has also been under discussion $8,46,47,51,57$. Further information on surface vacancies and also surface defects, e.g., at the surface boundaries could give a more thorough look at the surface interaction with hydroxyl and $\mathrm{CO}$ species. Also tailoring the properties of monoclinic zirconia by using promoters and dopants without changing its crystalline phase could elucidate the interaction. Advanced methods similar to Raman in the case of ceria ${ }^{93}$ might also provide surprisingly rich information.

With the adsorbed CO species the knowledge on especially the formate species deserves more investigation. The surface configuration of the species (monodentate, chelating or bridging bidentate) is unclear based on experimental observations, although bidentate species has been speculated and theoretical calculations suggest both chelating and bridging bidentate species. Also the enthalpy of formation for formate species has only been estimated theoretically, an experimental confirmation for it, e.g., with microcalorimetry, would be welcome. Some clarity on the kinetics of formate formation on terminal and multicoordinated hydroxyls or even the extent of the reaction on both types of hydroxyls could provide new insights related to catalysis. Operando-style experiments with combined surface and gas-phase quantification would provide valuable input on all of the surface species with $\mathrm{CO}$ and hydroxyls. Observing the surface species in the same setup under vacuum might enlighten the mechanism of surface reduction via oxy- gen removal and why evacuation is a more efficient reduction method than hydrogen treatment ${ }^{80}$.

To improve the modeling of carbon oxides, a better understanding of an active surface site is highly important to be able to set up more accurate computational surface models to better describe the complexity of the $\mathrm{ZrO}_{2}$ support/catalyst. This would not only impact on calculation of adsorption energies but would also influence on calculated frequencies. As long as the nature of an active site is not known exactly, a systematic approach, where, e.g., different surface models are investigated side by side, is a natural choice to obtain information of adsorption characteristics. To discover the active surface sites and to further improve the selectivity of catalysts, nanoshaped supports and catalysts with their surface regularity have proven an interesting alternative. The better the control over the surface sites, the better the catalyst selectivity. However, the control is only to be reached through monocrystalline nanoshapes as in polycrystalline shapes the surfaces are not controlled.

Growing monoclinic zirconia in the shape of nanofibres and nanorods has become gained some attention during the last 15 years, yet most of the shapes are polycrystalline. The preparation methods differ from traditional wet chemistry to prepare monoclinic zirconia powders. Nanorods have been prepared hydrothermally ${ }^{16,17}$ in an autoclave, resulting in nanorods of various sizes, the diameter in general some tens of nanometers and the length a few hundred nanometers, and the length- 
diameter ratio ranging from $c a .5$ up until 50 or even more.

Exposed faces of the nanoshapes should be characterized with advanced electron microscopy techniques (e.g. aberration-corrected TEM as in ${ }^{94}$ ) to determine the orientation of the exposed surfaces. Boucher et al. ${ }^{95}$ have tested different shapes of metal oxides with gold catalysts for steam reforming of methanol and water-gas shift, and they conclude that the different shapes show somewhat different activities. Li and Shen ${ }^{96}$ discuss widely the oxide shape effects in nanocatalysis, and they mention some of the unknown issues with metal deposition on oxide nanoshapes: whether the metal atoms are located on a single type of surface only. They also bring up that the nanoshapes might not be stable under the reaction conditions, this might also affect the metal-support interface, often considered to be the active site ${ }^{96}$.

\section{Conclusions}

Monoclinic zirconia surface has three kinds of coordinatively unsaturated cationic sites, two types of $\mathrm{Zr}^{4+}$ and one type of $\mathrm{Zr}^{3+}$, coordinatively unsaturated $\mathrm{Zr}^{4+}-\mathrm{O}^{2-}$ pairs, oxygen vacancies, terminal hydroxyls, and two types of multicoordinated hydroxyl species. The ratios of these sites can be modified with pretreatments by removing or adding oxygen and hydrogen to the surface through applying heat, vacuum or reactive atmospheres. The cationic sites are responsible for the linearly adsorbed $\mathrm{CO}$ species while formates are suggested to form preferably on a site where an unshielded zirconium ion is paired with a terminal hydroxyl species, assuming a bidentate formate. This would provide an explanation for the submonolayer quantities of formate on zirconia. The concentrations of active sites for linear $\mathrm{CO}$ and formate formation are of similar magnitude, corresponding to $c a$. 5\% of a monolayer or less, whereas the amount of hydroxyl species on the surface is roughly tenfold. The formates as well as hydroxyl species prefer the defect type of $\mathrm{Zr}^{4+}$ sites. The specific roles for $\mathrm{Zr}^{3+}$ and the terrace-type $\mathrm{Zr}^{4+}$ remain unclear. Other open questions include confirming the nature of the multicoordinated hydroxyls, the surface configuration of the formate species, and the energetics of formate formation. Nanoshapes might be a valuable tool in exploring the surface aspects related to formates and hydroxyls.

\footnotetext{
${ }^{a}$ Department of Biotechnology and Chemical Technology, Aalto University School of Chemical Technology, P.O. Box 16100, 00076 Aalto, Finland. Email: sonja.kouva@aalto.fi

${ }^{b}$ Department of Chemistry, Nanoscience Center, University of Jyväskylä, P.O. Box 35, 40014 Jyväskylä, Finland

${ }^{c}$ Faculty of Science \& Technology, University of Twente, P.O. Box 217, 7500 AE Enschede, The Netherlands.
}

\section{Acknowledgements}

The authors acknowledge funding from Academy of Finland and Finland Distinguished Professor Programme (FiDiPro) funded by the Finnish Funding Agency for Technology and Innovation (TEKES).

\section{References}

1 K. Tanabe and T. Yamaguchi, Catal. Today, 1994, 20, 185-198.

2 T. Yamaguchi, Catal. Today, 1994, 20, 199-218.

3 A. A. Tsyganenko and V. N. Filimonov, J. Mol. Struct., 1973, 19, 579589.

4 A. Christensen and E. Carter, Phys. Rev. B, 1998, 58, 8050-8064.

5 D. V. Pozdnyakov and V. N. Filimonov, Zh. Fiz. Khim., 1972, 46, 10111012.

6 T. M. Miller and V. H. Grassian, Catal. Lett., 1997, 46, 213-221.

7 Z.-Y. Ma, C. Yang, W. Wei, W.-H. Li and Y.-H. Sun, J. Mol. Catal. A: Chem., 2005, 227, 119-124.

8 C. Morterra, E. Giamello, L. Orio and M. Volante, J. Phys. Chem., 1990, 94, 3111-3116.

9 A. Trunschke, D. L. Hoang and H. Lieske, J. Chem. Soc., Faraday Trans., 1995, 91, 4441-4444.

10 N. B. Jackson and J. G. Ekerdt, J. Catal., 1986, 101, 90-102.

11 J. Li, J. Chen, W. Song, J. Liu and W. Shen, Appl. Catal., A, 2008, 334, 321-329.

12 C. A. Franchini, A. M. Duarte de Farias, E. M. Albuquerque, R. dos Santos and M. A. Fraga, Appl. Catal., B, 2012, 117-118, 302-309.

13 G. Águila, S. Guerrero and P. Araya, Catal. Comm., 2008, 9, 2550-2554.

14 K. Takanabe, K. Aika, K. Inazu, T. Baba, K. Seshan and L. Lefferts, J. Catal., 2006, 243, 263-269.

15 M. Benito, R. Padilla, L. Rodríguez, J. Sanz and L. Daza, J. Power Sources, 2007, 169, 167-176.

16 X.-L. Liu, I. Pappas, M. Fitzgerald, Y.-J. Zhu, M. Eibling and L. Pan, Mater. Lett., 2010, 64, 1591-1594.

17 R. Espinoza-González, D. Diaz-Droguett, J. Avila, C. Gonzalez-Fuentes and V. Fuenzalida, Mater. Lett., 2011, 65, 2121-2123.

18 C. Morterra, R. Aschieri and M. Volante, Mater. Chem. Phys., 1988, 20, 539-557.

19 M.-Y. He and J. G. Ekerdt, J. Catal., 1984, 87, 381-388.

20 D. Bianchi, T. Chafik, M. Khalfallah and S. J. Teichner, Appl. Catal., A, 1993, 105, 223-249.

21 M.-Y. He and J. G. Ekerdt, J. Catal., 1984, 87, 238-254.

22 S. T. Korhonen, M. Calatayud and A. O. I. Krause, J. Phys. Chem. C, 2008, 112, 16096-16102.

23 P. O. Graf, D. J. M. de Vlieger, B. L. Mojet and L. Lefferts, J. Catal., 2009, 262, 181-187.

24 W. Hertl, Langmuir, 1989, 5, 96-100.

25 K. T. Jung and A. T. Bell, J. Mol. Catal. A: Chem., 2000, 163, 27-42.

26 F. Ouyang, A. Nakayama, K. Tabada and E. Suzuki, J. Phys. Chem. B, 2000, 104, 2012-2018.

27 V. Bolis, C. Morterra, M. Volante, L. Orio and B. Fubini, Langmuir, 1990, 6, 695-701.

28 S. Kouva, J. Andersin, K. Honkala, J. Lehtonen, L. Lefferts and J. Kanervo, Phys. Chem. Chem. Phys., 2014, 16, 20650-20664.

29 E. Guglielminotti, Langmuir, 1990, 6, 1455-1460.

30 K. Pokrovski, K. T. Jung and A. T. Bell, Langmuir, 2001, 17, 4297-4303.

31 A. V. Radha, O. Bomati-Miguel, S. V. Ushakov, A. Navrotsky and P. Tartaj, J. Am. Ceram. Soc., 2009, 92, 133-140.

32 S. V. Ushakov and A. Navrotsky, Appl. Phys. Lett., 2005, 87, 164103.

18 | Journal Name, 2010, [vol], 1-19 
33 H. F. Holmes, E. L. Fuller Jr. and R. A. Beh, J. Colloid Interf. Sci., 1974, 47, 365-371.

34 J. Nawrocki, P. W. Carr, M. J. Annen and S. Froelicher, Anal. Chim. Acta, 1996, 327, 261-266.

35 K. Dyrek, A. Adamski and Z. Sojka, Ceram. Interfaces 2, 2001, pp. 241259.

36 K. Hadjiivanov, Identification and Characterization of Surface Hydroxyl Groups by Infrared Spectroscopy, Academic Press, 2014, vol. 57, pp. 99318.

37 J. Nawrocki, M. P. Rigney, A. McCormick and P. W. Carr, J. Chromatogr. A, 1993, 657, 229-282.

38 C. Morterra, L. Orio and C. Emanuel, J. Chem. Soc., Faraday Trans., 1990, 86, 3003-3013.

39 C. Morterra, L. Orio, V. Bolis and P. Ugliengo, Mater. Chem. Phys., 1991, 29, 457-466.

40 G. Cerrato, S. Bordiga, S. Barbera and C. Morterra, Appl. Surf. Sci., 1997, 115, 53-65.

41 K. T. Jung, Y. G. Shul and A. T. Bell, Korean J. Chem. Eng., 2001, 18, 992-999.

42 K.-D. Jung and A. T. Bell, J. Catal., 2000, 193, 207-223.

43 I. A. Fisher, H. C. Woo and A. T. Bell, Catal. Lett., 1997, 44, 11-17.

44 N. E. Tret'yakov, D. V. Pozdnyakov, O. M. Oranskaya and V. N. Filimonov, Russ. J. Phys. Chem., 1970, 44, 596-600.

45 R. G. Silver, C. J. Hou and J. G. Ekerdt, J. Catal., 1989, 118, 400-416.

46 M. J. Torralvo, M. A. Alario and J. Soria, J. Catal., 1984, 86, 473-476.

47 M. Anpo and S. C. Moon, Res. Chem. Intermed., 1999, 25, 1-12.

48 J. Kondo, H. Abe, Y. Sakata, K.-i. Maruya, K. Domen and T. Onishi, J. Chem. Soc., Faraday Trans. 1, 1988, 84, 511-519.

49 J. Kondo, Y. Sakata, K. Domen, K.-i. Maruya and T. Onishi, J. Chem. Soc., Faraday Trans., 1990, 86, 397-401.

50 M. Bensitel, O. Saur, J. C. Lavalley and G. Mabilon, Mater. Chem. Phys., 1987, 17, 249-258.

51 E. Giamello, M. Volante, B. Fubini, F. Geobaldo and C. Morterra, Mater. Chem. Phys., 1991, 29, 379-386.

52 V. Bolis, G. Cerrato, G. Magnacca and C. Morterra, Thermochim. Acta, 1998, 312, 63-77.

53 D. Bianchi, J.-L. Gass, M. Khalfallah and S. J. Teichner, Appl. Catal., A, 1993, 101, 297-315.

54 X. Mugniery, T. Chafik, M. Primet and D. Bianchi, Catal. Today, 1999, 52, 15-22.

55 O. Dulaurent and D. Bianchi, Appl. Catal., A, 2001, 207, 211-219.

56 J. Erkelens, H. T. Rijnten and S. H. Eggink- Du Burck, Recl. des Trav. Chim. des Pays-Bas, 1972, 91, 1426-1432.

57 M. G. Cattania, A. Gervasini, F. Morazzoni, R. Scotti and D. Strumolo, J. Chem. Soc. Faraday Trans. 1, 1989, 85, 801-812.

58 K. Hadjiivanov and J.-C. Lavalley, Catal. Comm., 2001, 2, 129-133.

59 T. Yamaguchi, Y. Nakano and K. Tanabe, Bull. Chem. Soc. Jpn., 1978, 51, 2482-2487.

60 T. Yamaguchi, H. Sasaki and K. Tanabe, Chem. Lett., 1973, 9, 1017-1018.

61 P. A. Agron, E. L. Fuller Jr. and H. F. Holmes, J. Colloid Interf. Sci., 1975, 52, 553-561.

62 E.-M. Köck, M. Kogler, T. Bielz, B. Klötzer and S. Penner, J. Phys. Chem. C, 2013, 117, 17666-17673.

63 T. Merle-Méjean, P. Barberis, S. B. Othmane, F. Nardou and P. E. Quintard, J. Eur. Ceram. Soc., 1998, 18, 1579-1586.

64 P. D. L. Mercera, J. van Ommen, E. B. M. Doesburg, A. J. Burggraaf and J. R. H. Ross, Appl. Catal., 1991, 71, 363-391.

65 K.-H. Jacob, E. Knözinger and S. Benfer, J. Mater. Chem., 1993, 3, 651657.

66 D. Martin and D. Duprez, J. Phys. Chem., 1996, 100, 9429-9438.

67 S. T. Korhonen, M. Calatayud and A. O. I. Krause, J. Phys. Chem. C, 2008, 112, 6469-6476.
68 G. Mogilevsky, C. J. Karwacki, G. W. Peterson and G. W. Wagner, Chem. Phys. Lett., 2011, 511, 384-388.

69 A. Ignatchenko, D. G. Nealon, R. Dushane and K. Humphries, J. Mol. Catal. A: Chem., 2006, 256, 57-74.

70 A. N. Kharlanov, E. V. Lunina and V. V. Lunin, Russ. J. Phys. Chem., 1997, 71, 1504-1509.

71 A. A. Tsyganenko and V. N. Filimonov, Spectrosc. Lett., 1972, 5, 477487.

72 K. Yardley, Mineral. Mag., 1926, 21, 169-175.

73 D. K. Smith and W. Newkirk, Acta Crystallogr., 1965, 18, 983-991.

74 O. Syzgantseva, M. Calatayud and C. Minot, J. Phys. Chem. C, 2010, 114, 11918-11923.

75 J. D. McCullough and K. N. Trueblood, Acta Crystallogr., 1959, 12, $507-$ 511.

76 C. Warble, Ultramicroscopy, 1984, 15, 301-309.

77 W. Piskorz, J. Gryboś, F. Zasada, S. Cristol, J.-F. Paul, A. Adamski and Z. Sojka, J. Phys. Chem. C, 2011, 115, 24274-24286.

78 K. Momma and F. Izumi, J. Appl. Crystallogr., 2011, 44, 1272-1276.

79 M. C. Deibert and R. Kahraman, Appl. Surf. Sci., 1989, 37, 327-336.

80 K.-O. Axelsson, K.-E. Keck and B. Kasemo, Appl. Surf. Sci., 1986, 25, 217-230.

81 K.-H. Jacob, E. Knözinger and S. Benfer, J. Chem. Soc., Faraday Trans., 1994, 90, 2969-2975.

82 O. A. Syzgantseva, M. Calatayud and C. Minot, J. Phys. Chem. C, 2012, 116, 6636-6644.

83 M. Van Thiel, E. D. Becker and G. C. Pimentel, J. Chem. Phys., 1957, 27, 486-490.

84 M. L. Cerón, B. Herrera, P. Araya, F. Gracia and A. Toro-Labbé, J. Mol. Model., 2013, 19, 2885-2891.

85 I. M. Iskandarova, A. A. Knizhnik, E. A. Rykova, A. A. Bagatur'yants, B. V. Potapkin and A. A. Korkin, Microelectron. Eng., 2003, 69, 587-593.

86 G. N. Vayssilov, M. Mihaylov, P. S. Petkov, K. I. Hadjiivanov and K. M. Neyman, J. Phys. Chem. C, 2011, 115, 23435-23454.

87 F. Ouyang, J. N. Kondo, K.-c. Maruya and K. Domen, J. Chem. Soc., Faraday Trans., 1996, 92, 4491-4495.

88 G. Busca, J. Lamotte, J. C. Lavalley and V. Lorenzelli, J. Am. Chem. Soc., 1987, 109, 5197-5202.

89 G. Busca and V. Lorenzelli, Mater. Chem., 1982, 7, 89-126.

90 T. Shido and Y. Iwasawa, J. Catal., 1992, 136, 493-503.

91 T. Shido and Y. Iwasawa, J. Catal., 1993, 141, 71-81.

92 J. Zhu, J. van Ommen, H. Bouwmeester and L. Lefferts, J. Catal., 2005, 233, 434-441.

93 S. Agarwal, X. Zhu, E. J. M. Hensen, L. Lefferts and B. L. Mojet, J. Phys. Chem. C, 2014, 118, 4131-4142.

94 S. Agarwal, L. Lefferts, B. L. Mojet, D. A. J. M. Ligthart, E. J. M. Hensen, D. R. G. Mitchell, W. J. Erasmus, B. G. Anderson, E. J. Olivier, J. H. Neethling and A. K. Datye, ChemSusChem, 2013, 6, 1898-906.

95 M. B. Boucher, S. Goergen, N. Yi and M. Flytzani-Stephanopoulos, Phys. Chem. Chem. Phys., 2011, 13, 2517-27.

96 Y. Li and W. Shen, Chem. Soc. Rev., 2014, 43, 1543-74.

This journal is $\odot$ The Royal Society of Chemistry [year] Journal Name, 2010, [vol], 1-19 | 19 